\title{
Myogenic Differentiation of Mouse Embryonic Stem Cells That Lack a Functional Pax7 Gene
}

\author{
Areta M. Czerwinska, Iwona Grabowska,, Karolina Archacka,, Joanna Bem,, Barbara Swierczek, \\ Anita Helinska, Wladyslawa Streminska, Anna Fogtman,2 Roksana Iwanicka-Nowicka,,3 \\ Marta Koblowska, ${ }^{2,3}$ and Maria A. Ciemerych ${ }^{1}$
}

The transcription factor Pax7 plays a key role during embryonic myogenesis and sustains the proper function of satellite cells, which serve as adult skeletal muscle stem cells. Overexpression of $\operatorname{Pax} 7$ has been shown to promote the myogenic differentiation of pluripotent stem cells. However, the effects of the absence of functional Pax7 in differentiating embryonic stem cells (ESCs) have not yet been directly tested. Herein, we studied mouse stem cells that lacked a functional Pax7 gene and characterized the differentiation of these stem cells under conditions that promoted the derivation of myoblasts in vitro. We analyzed the expression of myogenic factors, such as myogenic regulatory factors and muscle-specific microRNAs, in wild-type and mutant cells. Finally, we compared the transcriptome of both types of cells and did not find substantial differences in the expression of genes related to the regulation of myogenesis. As a result, we showed that the absence of functional Pax7 does not prevent the in vitro myogenic differentiation of ESCs.

\section{Introduction}

$\mathrm{U}$

NDER PHYSIOLOGICAL CONDITIONS, skeletal muscle regeneration relies on the presence of satellite cells [1-3]. In injured muscles, these cells become activated, proliferate, and differentiate into myoblasts that fuse and reconstruct muscle fibers (reviewed in Yablonka-Reuveni and Scharner and Zammit [4,5]). Satellite cells originate from myogenic precursor cells (MPCs) that are specified during differentiation of the somitic mesoderm and are characterized by the expression of two Pax genes, Pax3 and Pax7 [6-8]. The differentiation of MPCs into skeletal myoblasts is associated with the progressive downregulation of Pax 3 and Pax 7 and the induction of the expression of the myogenic regulatory factors (MRFs) MyoD, Myf5, myogenin, and Mrf4 (eg, [913]). As myogenesis progresses, a subpopulation of MPCs retain Pax7 expression [14]. These cells do not differentiate, but instead become satellite cells that remain quiescent until they are activated $[15,16]$. Under physiological conditions, satellite cells are the major source of cells that ensure the proper regeneration of skeletal muscle. However, in aging organisms and under pathological conditions, such as massive muscle injuries and diseases (eg, Duchenne's muscular dystrophy), they might not be sufficient. These conditions might be ameliorated by the transplantation of cells derived from pluripotent stem cells, such as embryonic stem cells (ESCs) or induced pluripotent stem cells (iPSCs; for a review, see Grabowska et al. [17]).

During embryonic myogenesis, as well as in injured or regenerating adult muscles, the sequential expression of MRFs regulates myoblast differentiation and the formation of myotubes that can form myofibers. The pattern of MRF induction is characteristic of both embryonic and adult myogenesis, including the differentiation of satellite cells that are activated within injured and regenerating muscles. In developing embryos, Pax 3 and Pax 7 affect $M y o D$ expression by regulating myogenic differentiation $[10,18]$. In quiescent satellite cells, Pax7 induces the expression of genes such as Inhibitor of differentiation 3 (Id3) [19], which prevents $M y o D$ expression and inhibits apoptosis [11,20]. Pax 7 also regulates the expression of Myf5 mRNA transcripts [21], which are present in satellite cells but remain localized within mRNPs and, for this reason, are unavailable for translation [22].

Among the factors that regulate myogenesis are also small noncoding microRNAs that can negatively regulate

\footnotetext{
${ }^{1}$ Department of Cytology, Faculty of Biology, Institute of Zoology, University of Warsaw, Warsaw, Poland.

${ }^{2}$ Laboratory of Microarray Analysis, Institute of Biochemistry and Biophysics, Polish Academy of Sciences, Warsaw, Poland.

${ }^{3}$ Department of Systems Biology, Faculty of Biology, University of Warsaw, Warsaw, Poland.

(C) Areta M. Czerwinska et al., 2016; Published by Mary Ann Liebert, Inc. This Open Access article is distributed under the terms of the Creative Commons Attribution Noncommercial License (<http://creativecommons.org/licenses/by-nc/4.0/>) which permits any noncommercial use, distribution, and reproduction in any medium, provided the original author(s) and the source are credited.
} 
mRNA transcript levels either by leading to their degradation or by inhibiting translation. For example, miR27 has been shown to regulate the expression of $\operatorname{Pax3}$, but not $\operatorname{Pax} 7$ [23], and both miRl and miR206 can downregulate the expression of Pax7 [24,25]. The relationship between MRFs and microRNAs has been shown to be reciprocal. Myf5, MyoD, MEF2, and myogenin impact at the level of what are known as myoMiRs, that is, miR1, miR133a, miR133b, and miR206 [26-28]. Thus, the interplay between Pax7, MRFs, and microRNAs creates an additional level of regulation of myogenic differentiation.

The role of Pax proteins in skeletal muscle development has been established by the genetic ablation of the Pax3 and Pax7 genes. In Pax3-null mouse embryos, the development of limb muscles was greatly affected because of defects in the migration of skeletal muscle cells [7]. Pax7 depletion leads to premature death during postnatal development as mutant mice fail to survive beyond 2-3 weeks of age because of a neurological phenotype [29]. In $\operatorname{Pax} 7$ mutant mice, skeletal muscles develop; however, they have a significantly lower mass than wild-type littermates [29-31]. The absence of functional Pax 7 does not totally prevent secondary myogenesis [32], but skeletal muscle fibers of mice depleted of Pax7positive cells exhibit a typical phenotype of primary myofibers [33]. The population of satellite cells that reside in the muscles of newborn Pax7-null mice progressively decreases in maturing animals, which prevents proper muscle growth [31]. Thus, in Pax7-null mice, the number of satellite cells is lower both in skeletal muscles [14,31] and in the tunica muscularis of the esophagus [34].

In adult mice, the role of $\operatorname{Pax} 7$ was tested in experiments that involved the selective deletion of this gene in satellite cells alone. In animals younger than 21 days old, skeletal muscle regeneration was shown to depend upon Pax7 [35]. However, the role of Pax7 in skeletal muscles of older mice remains the subject of debate. Some lines of evidence indicate that this factor is dispensable for proper satellite cell function [35], while other data suggest that it is necessary for myogenic differentiation, even in mice older than 21 days [36,37]. Thus, differences between the function of Pax7 during embryonic, early postnatal, and adult myogenesis are strongly suggested (reviewed in Wang and Conboy and Relaix and Zammit [38,39]). Furthermore, lack of satellite cells, caused either by a germline mutation in Pax7 or the conditional depletion of satellite cells, results in the failure of skeletal muscle regeneration [40-43].

Determining the role of $\mathrm{Pax} 7$ in myogenic differentiation is crucial for understanding both the biology of MPCs and satellite cells, as well as other stem cells that can enter a myogenic program. Among these cells are those that are considered to be potential sources for cell therapies to treat injured or disease-affected skeletal muscles, that is, ESCs and iPSCs. Several experiments have established that these two types of cells can produce any type of tissue in vivo, either in chimeric animals [44] or in animals generated with the aid of a tetraploid complementation technique [45-47] or in teratomas [48]. It is commonly accepted that in vitro many if not all required cell types can be derived from ESCs and iPSCs. However, for many years, protocols that enabled the efficient derivation of myogenic cells from pluripotent stem cells have not been available. Only recently, significant progress has been made. Several research groups have established protocols based on the knowledge of embryonic myogenesis. These methods provide favorable in vitro conditions for the robust myogenic differentiation of pluripotent stem cells. In two such studies, the manipulation of Wnt signaling and FGF-2 stimulation of pluripotent stem cells led to efficient myogenic differentiation $[49,50]$. However, the functionality of the obtained myogenic cells has not yet been tested in vivo. Recently, Chal et al. presented a sophisticated culture scheme that mimicked the environmental characteristics of somitogenesis and further stages of myogenesis. Importantly, that protocol allowed for the successful generation of contractile myofibers and the derivation of an abundance of cells that can support skeletal muscle regeneration [51]. Thus, many previously published experiments have been based on the assumption that the mechanisms that govern cellular differentiation in vivo are also operational during the in vitro differentiation of stem cells. If this is true, one must ask whether this process will be $\operatorname{Pax} 7$ dependent in the case of pluripotent stem cells, as has been suggested for embryonic and early postnatal development, or whether it will be Pax7 independent, as suggested for myogenic differentiation that occurs in adult mice [35,38]. To answer this question, ESCs carrying a mutated form of the $\operatorname{Pax} 7$ gene were generated and analyzed.

\section{Materials and Methods}

Animal studies were approved by the local ethics committee No. 1 in Warsaw, Poland, according to the European Union Directive on the approximation of laws, regulations, and administrative provisions of the Member States regarding the protection of animals used for experimental and scientific purposes [52,53]. All mice were raised on the premises and were maintained under a 12-h light/12-h dark cycle. ESCs used in this present study were either commercially available D3 line or four ESC lines that were derived by us, that is, Pax7wt1 and Pax 7wt 2 that expressed functional Pax7, and Pax7ko1 and Pax7ko2 that lacked a functional $\operatorname{Pax} 7$ gene. For each analysis, at least three independent experiments were performed.

\section{Preparation of feeder cells}

Feeder cells, that is, inactivated mouse embryonic fibroblasts (MEFs), were prepared according to Robertson [54]. In brief, primary MEFs were derived from 13.5-day-old embryos isolated from $\mathrm{F} 1(\mathrm{C} 57 \mathrm{~B} 16 \mathrm{~N} \times \mathrm{CBA} / \mathrm{H})$ females mated with males from the same cross. MEFs were cultured in Dulbecco's modified Eagle's medium (DMEM) (with $4.500 \mathrm{mg} / \mathrm{L}$ glucose; Gibco) supplemented with $10 \%$ heatinactivated fetal bovine serum (FBS; Gibco) and penicillin and streptomycin (5,000 U/mL each; Gibco). Confluent MEFs were inactivated by treatment with mitomycin C $(10 \mu \mathrm{g} / \mathrm{mL}$; Sigma-Aldrich) for $2 \mathrm{~h}$. Growth-arrested MEFs were frozen and plated one day before blastocyst plating or ESC seeding.

\section{Generation and in vitro culture of ESCs}

C57B16N females carrying a mutation in one allele of the Pax7 gene were crossed with 129Sv males. Resulting progeny were genotyped. In brief, genomic DNA was isolated from the tail tips of 2-week-old mice that were placed in $100 \mu \mathrm{L} 10 \%$ Chelex 100 (Bio-Rad) solution in deionized 
water at $98^{\circ} \mathrm{C}$ for $15 \mathrm{~min}$. Next, supernatants containing DNA were collected and $1 \mu \mathrm{L}$ of this solution was used for PCR analysis using REDTaq ReadyMix (Sigma-Aldrich) and primers according to previously described conditions [29]. PCR products were separated using $1.5 \%$ agarose gel electrophoresis (Bio-Rad) and visualized with ethidium bromide (1 mg/mL; Sigma-Aldrich). Agarose gels were analyzed with GelDoc 2000 (Bio-Rad) using Quantity One software (Bio-Rad). Wild-type alleles were represented by a $200 \mathrm{bp}$ band and the knockout allele by a $600 \mathrm{bp}$ band [29].

For superovulation, 6-week-old F1 $(\mathrm{C} 57 \mathrm{~B} 16 \mathrm{~N} \times 129 \mathrm{~Sv})$ $\mathrm{Pax}^{+/-}$females were induced by injecting $10 \mathrm{IU}$ pregnant mare's serum gonadotropin (PMSG; Folligon, Intervet) followed $48 \mathrm{~h}$ later by the injection of $10 \mathrm{IU}$ human chorionic gonadotropin (hCG; Folligon, Intervet). Next, females were allowed to mate with males of the same cross and genotype. Blastocysts were collected $96 \mathrm{~h}$ after hCG injection by flushing the uterus with an M2 medium [55] and then were transferred to single wells of 96-well culture dishes covered with gelatin $(0.2 \% \mathrm{w} / \mathrm{v}$; Sigma-Aldrich) and a feeder layer of inactivated MEFs.

The medium for ESC derivation was composed of KnockOut DMEM (Gibco) supplemented with 10\% serum replacement (SR; Gibco) with the addition of nonessential amino acids (0.1 mM; Gibco), L-glutamine ( $2 \mathrm{mM}$; Gibco), $\beta$ mercaptoethanol (0.1 mM; Sigma-Aldrich), penicillin and streptomycin $(5,000 \mathrm{U} / \mathrm{mL}$ each; Gibco), murine leukemia inhibitory factor (LIF, 1,000 IU/mL; ESGRO, Chemicon International), and $12.5 \mu \mathrm{M}$ MEK1 inhibitor (PD98059; Sigma-Aldrich). After 3-4 days of culture, blastocysts formed outgrowths that were then disaggregated enzymatically and mechanically by incubation with $0.25 \%$ trypsin/ EDTA (Gibco) for 5-10 min and also by pipetting. Resulting cell suspensions were transferred onto inactivated MEFs and were inspected daily for the appearance of primary colonies. Cultures that contained ESCs were expanded, processed for genotyping and karyotyping, and then frozen for further investigation. Established ESC lines were cultured in KnockOut DMEM that contained all supplements described earlier, except for PD98059, and were supplemented with 15\% heatinactivated FBS (Performance Plus; Gibco) instead of SR.

Some analyses, for example, genotyping or generation of embryoid bodies (EBs), required the removal of MEFs from the ESC cultures. To do so, cultures were incubated in $0.05 \%$ trypsin/EDTA for 3-5 min, cells were suspended in a culture medium, plated again onto a culture dish covered with $0.2 \%$ gelatin, and then were incubated at $37^{\circ} \mathrm{C}$ for 20 min, which allowed MEFs to attach to the dish. The ESCcontaining medium was transferred to another gelatin covered culture dish or was used for EBs generation. If needed, preplating was repeated.

\section{In vitro differentiation of ESCs}

EBs were generated using the hanging drop technique. Briefly, 800 ESCs were suspended in $30 \mu \mathrm{L}$ drops of KnockOut DMEM that lacked LIF, that is, KnockOut DMEM that contained $15 \%$ heat-inactivated FBs, L-glutamine, nonessential amino acids, $\beta$-mercaptoethanol, and penicillin and streptomycin. Drops were placed onto covers of culture dishes that were filled with phosphate-buffered saline (PBS) and cultured at $37^{\circ} \mathrm{C}$ allowing for EBs formation. At day 2 of culture in hanging drops, EBs were transferred to lowadhesive dishes (Medlab) allowing for their culture in suspension. At day 7 of culture, $30 \mathrm{EBs}$ were transferred onto $0.2 \%$ gelatin-coated coverslips to allow for outgrowth formation. Control cultures were conducted either in KnockOut DMEM or DMEM followed by DMEM and F12 (1:1; Gibco), which lacked LIF from day 1 until 21 and were supplemented with decreasing concentrations of FBS (see schematic diagram, Fig. 2). Myogenic differentiation was also induced by culturing cells in the medium containing various FBS concentrations, which were also complemented with additional supplements (see schematic diagram, Fig. 3). Between days 2 and 7, EB culture media were supplemented with retinoic acid (RA, $30 \mathrm{nM}$ in DMSO; Sigma) and insulin, transferrin, and selenium (ITS, 1\%, Gibco) [56,57]. Subsequently, cells were cultured in KnockOut DMEM that lacked LIF until day 10 of culture, when DMEM containing $20 \%$ heat-inactivated FBS (Gibco), and penicillin and streptomycin, was used. Next, the concentration of FBS in the culture medium was reduced to $10 \%$ (day 13) and then $5 \%$ (day 14). Starting from day 15, EB outgrowths were cultured in a medium composed of DMEM and F12 (1:1; Gibco) supplemented with 1\% N2 (Gibco) and penicillin and streptomycin, but that lacked FBS (adapted protocols of [58] and S. Tajbakhsh, personal communication). Culture media were changed every 2-3 days. EBs and EB outgrowths were analyzed at 2, 5, 7, 14, and 21 days of culture.

Generation of cardiomyocytes was carried out as previously described [59] (see schematic diagram, Fig. 2). In brief, 400 ESCs were placed in $20 \mu \mathrm{L}$ hanging drops of IMDM supplemented with $20 \%$ heat-inactivated FBS (Performance Plus), L-glutamine, nonessential amino acids, monothioglycerol $(450 \mu \mathrm{g}$; Sigma-Aldrich), and penicillin and streptomycin, and were cultured for 2 days. Next, EBs were cultured in suspension in low-adhesive dishes. At day 5, EBs were plated onto $1 \%$ gelatin-coated coverslips to allow for outgrowth formation. The culture medium was changed every three days. At 12 days of culture, outgrowths were collected.

\section{In vivo differentiation of ESCs-teratoma formation}

ESCs were cultured under standard conditions to support pluripotency. After 4-5 days of culture, ESC colonies were disaggregated in $0.05 \%$ trypsin/EDTA for 3-5 min, washed once in the culture medium, and then twice in PBS. Finally, $10 \times 10^{6}$ cells were suspended in $100 \mu \mathrm{L} 0.9 \% \mathrm{NaCl}$ and injected subcutaneously to isoflurane-anesthetized 3-month-old F1 (C57B16N $\times 129 \mathrm{~Sv})$ males. Mice were inspected daily and teratomas were isolated when they were $1 \mathrm{~cm}$ in diameter. Immediately after isolation, teratomas were either frozen in liquid nitrogen-cooled isopentane and then stored at $-80^{\circ} \mathrm{C}$ or were fixed in $4 \%$ paraformaldehyde (PFA; Sigma-Aldrich) in PBS at $4{ }^{\circ} \mathrm{C}$, embedded in paraffin replacement, that is, paraplast, and processed as described previously [60]. For each cell line, at least 3 teratomas were analyzed.

\section{Genotyping and karyotyping of ESCs}

ESC colonies were disaggregated by incubation in $0.05 \%$ trypsin/EDTA for 3-5 min, washed in PBS, pelleted, and frozen at $-80^{\circ} \mathrm{C}$. Genomic DNA was isolated by stirring ESCs in $100 \mu \mathrm{L}$ of $10 \%$ Chelex 100 solution in deionized water at $98^{\circ} \mathrm{C}$ for $15 \mathrm{~min}$, as described earlier. Reactions 
were carried out as described previously for genotyping of animals. Karyotyping required ESC colonies to be incubated in a medium that contained $10 \mathrm{mg} / \mathrm{mL}$ colchicine (SigmaAldrich) at $37^{\circ} \mathrm{C}$ for $1.5 \mathrm{~h}$. Next, ESCs were disaggregated in $0.05 \%$ trypsin/EDTA for $3-5 \mathrm{~min}$, washed in PBS, suspended and incubated in $1 \mathrm{~mL} 0.56 \% \mathrm{KCl}$ (Sigma-Aldrich) at room temperature for $20 \mathrm{~min}$, and then fixed with methanol:acetic acid solution $(3: 1)$ at $4^{\circ} \mathrm{C}$ for $16 \mathrm{~h}$. Finally, ESCs were dropped onto warm slides and stained with the Giemsa reagent (Merck) according to the manufacturer's protocol. Next, specimens were dehydrated in HistoChoice (SigmaAldrich), mounted with the VectaMount Mounting Medium (Vector Laboratories), and analyzed using transmitted light microscopy (Axioskop; Zeiss). For each ESC line, at least 30 metaphase plates were analyzed.

\section{$R N A$ isolation, $R T-P C R$, and $q P C R$ (mRNA and microRNA) assays}

For mRNA transcript analysis by RT-PCR, RNA was isolated from undifferentiated ESCs and EBs using a High Pure RNA Isolation kit (Roche). Next, $0.2 \mu \mathrm{g}$ of total RNA was used and reaction was carried out with the Titan One Tube RT-PCR System (Roche) and customized primers according to conditions described previously [61]. PCR products were separated using $2 \%$ agarose gel electrophoresis and analyzed as indicated earlier. For qPCR, total RNA was isolated from undifferentiated ESCs, EBs, and EB outgrowths cultured in control media or media supplemented with RA and ITS, and also from 13.5-day-old embryos (obtained according to [62]) using the mirVana ${ }^{\mathrm{TM}}$ miRNA Isolation Kit (Ambion) and DNAse treated using TURBO DNAse (Ambion). Reverse transcription for mRNA analysis was performed using $0.5 \mu \mathrm{g}$ of total RNA and the RevertAid First-Strand cDNA Synthesis Kit (Thermo Fisher Scientific) according to the manufacturer's instructions. The qPCR assays were performed using the following specific TaqMan ${ }^{\circledR}$ probes: Mm02019550_ s1 (Nanog), Mm03053810_s1 (Sox2), Mm00438930_m1 (Fgfr1), Mm00443081_m1 (Pax6), Mm01976556_s1 (Foxa2), Mm01318252_m1 (T), Mm00440701_m1 (Pdgfr $\alpha)$, Mm00435493_m1 (Pax3), Mm00440387_m1 (MyoD1), Mm00446194_m1 (Myog), Mm01319006_g1 (Myh7), Mm00477791_m1 (Nfix), Mm00468267_m1 (Eno3), and Mm01205647_g1 (Actb) using the TaqMan Gene Expression Master Mix (Life Technologies) and a LightCycler 96 instrument (Roche). Data were collected and analyzed using LightCycler 96 SW1.1 software (Roche). For each analysis, three independent experiments were performed. For microRNA analysis, reverse transcription was performed with a TaqMan MicroRNA Reverse Transcription Kit (Applied Biosystems). The qPCR assays were performed using TaqMan (mmu-let-7a-5p, mmu-miR-145a-5p, mmu-miR-206-3p, mmu-miR-294-3p, mmu-miR-181a-5p, mmu-miR-1a-3pmmumiR-133a-3pmmu-miR-133b-3p, U6 snRNA mouse Cat. \# 4440887; Applied Biosystems), using a LightCycler $^{\circledR} 96$ System. Ddct analysis was performed according to Livak [63].

\section{Microarray analysis}

For microarray analyses, total RNA was isolated from undifferentiated ESCs (day 0), EBs (day 7 of culture), and EB outgrowths (day 21 of culture) cultured in control media or media supplemented with RA and ITS. A total of four independent samples were collected for each time point analyzed. RNA was isolated using a High Pure RNA Isolation kit (Roche). Next, the RNA integrity was assessed using a 2100 Bioanalyzer (Agilent Technologies) with an RNA 6000 Nano Lab Chip kit (Agilent Technologies). All RNA samples had an integrity number that was greater than 8.5. The Ambion ${ }^{\circledR}$ WT Expression Kit (Ambion) and GeneChip ${ }^{\circledR}$ WT Terminal Labeling and Controls Kit (Affymetrix) were used according to the manufacturer's instructions for target preparation on the Affymetrix ${ }^{\circledR}$ Mouse Gene 2.1 ST Array Strip. Fragmented labeled cDNA samples were hybridized to the array and scanned using an Affymetrix GeneAtlas Imaging station. The intensity signals for each probe set were written by Affymetrix software into ".cel", files. All procedures were performed according to the manufacturer's instructions. The ".cel" files were imported into the Partek Genomic Suite v 6.6 software using RMA (Robust Multiarray Averaging). During this step, background correction was applied based on the global distribution of the PM (perfect match) probe intensities and the affinity of each probe (based on sequences) was calculated. Furthermore, the probe intensities were quantile normalized [64], $\log 2$ transformed, and a median polish summarization of each probe set was applied. Then, a qualitative analysis was performed (ie, Principal Component Analysis) to identify outliers and artifacts on the microarray. After quality control, analysis of variance (ANOVA) was performed on the data set, which allowed for the creation of lists of significantly and differentially expressed genes between biological variants. The selected lists were subjected to cluster analysis to identify genes and samples with similar profiles using an unsupervised hierarchical clustering algorithm. Clusters were calculated based on standardized raw intensities that were shifted to a mean of zero and scaled to a standard deviation of one. Furthermore, the color scale among all heat maps was set to a range of -3 to 3 to equalize the dynamic ranges of all intensity plots. Data discussed in this publication have been deposited in the NCBI Gene Expression Omnibus and are accessible through GEO Series accession number GSE66483 (www.ncbi.nlm.nih.gov/geo/query/acc.cgi?acc=GSE66483).

\section{Immunolocalization}

ESCs and EB outgrowths were fixed with 3\% PFA in PBS at room temperature for $10 \mathrm{~min}$ and then were permeabilized with $0.5 \%$ Triton-X 100 (Sigma-Aldrich) in PBS at room temperature for $5 \mathrm{~min}$. Nonspecific antibody binding was blocked by incubation in $3 \%$ bovine serum albumin (BSA; Sigma-Aldrich) in PBS at room temperature for $1 \mathrm{~h}$. Next, primary antibodies were diluted with $0.5 \%$ BSA in PBS and incubated with cells at $4{ }^{\circ} \mathrm{C}$ overnight. Primary antibodies against the following epitopes were used: Oct-4 (Santa Cruz Biotechnology; diluted 1:100), Nanog (Cosmo Bio Co.; diluted 1:200), myosin heavy chain (DSHB, diluted 1:10), MyoD (Santa Cruz Biotechnology; diluted 1:200), and cardiac Troponin T (Abcam; diluted 1:100). The next day, specimens were incubated with appropriate secondary antibodies conjugated with Alexa 488 (Molecular Probes) or Alexa 595 (Molecular Probes) diluted 1:200 and DRAQ5 diluted $1: 1,000$ in $0.5 \%$ BSA in PBS at room temperature for $2 \mathrm{~h}$. Specimens were washed in PBS and mounted using the 
Fluorescent Mounting Medium (Dako). The specificity of primary antibodies was confirmed by incubating ESCs and EB outgrowths with secondary antibodies alone. Specimens were analyzed using an Axiovert 100M scanning confocal microscope (Zeiss) equipped with LSM 510 software. Figures were assembled using Adobe Photoshop CS6 Extended.

\section{Flow cytometry analysis}

ESCs without feeders were washed and fixed with 3\% PFA in PBS at room temperature for $10 \mathrm{~min}$. Unspecific antibody binding was prevented by incubation in $100 \mu \mathrm{L}$ of $0.5 \% \mathrm{BSA}$ in PBS at $4^{\circ} \mathrm{C}$ for $30 \mathrm{~min}$. Then, $10 \mu \mathrm{L}$ of antibodies against SSEA-1 was added (conjugated with Alexa 488; Santa Cruz Biotechnology). After a 1-h incubation at $4^{\circ} \mathrm{C}$, cells were washed with PBS, filtered through $35 \mu \mathrm{m}$ pores, and analyzed using a FACSCalibur (Becton Dickinson) with CellQuest software (Becton Dickinson). All analyzes were accompanied by appropriate negative and isotype controls.

\section{Histological analysis}

Using a cryostat, $10-\mu \mathrm{m}$-thick sections were obtained from frozen teratomas (Microm HM 505N; Microm International $\mathrm{GmbH}$ ), air-dried, stained with Harris's hematoxylin (SigmaAldrich) and eosin Y (Sigma-Aldrich) for $7 \mathrm{~min}$, and mounted in aqueous permanent mounting agent for microscopy (Dako). Paraplast sections were stained with Harris's hematoxylin, Masson's Trichrome (Sigma-Aldrich), or Harris's hematoxylin and Gomori Trichrome (Sigma-Aldrich) according to the manufacturer's instructions. Sections were analyzed using a Nikon TE200 microscope (Nikon Instruments) and NIS Elements software.

\section{Results}

\section{Characterization of mouse ESCs that lack functional Pax7}

To directly test the role of Pax7 in the myogenic differentiation of pluripotent stem cells, we derived mouse ESCs that lack a functional Pax7 transcription factor. To this point, we used previously generated $\operatorname{Pax} 7^{1 /-}$ mice [29] on a C57B16N background and crossed them with $129 \mathrm{~Sv}$ mice, that is, a strain of mice permissive for the establishment of ESC lines [65]. We used F1 (CB76BIN $\times 129 \mathrm{~Sv})$ animals with a $\mathrm{Pax}^{+/-}$genotype to generate blastocysts. The resulting wildtype and mutant ESC lines were genotyped (Fig. 1A) and karyotyped. Finally, based on the chromosome count, two wild-type (Pax7wt1 and Pax7wt2) and two mutant (Pax7ko1 and Pax7ko2) cell lines were chosen for further analyses. These ESCs were chosen based on the highest proportion of $2 \mathrm{n}$ metaphase plates ( 40 chromosomes), which was $97 \%$ for Pax7wt1, 94.6\% for Pax7wt2, 87.5\% for Pax7ko1, and 80\% for Pax7ko2 ESCs. These four selected cell lines were carefully analyzed to document their pluripotent characteristics. Their in vitro characteristics were compared with analyses of the commercially available D3 ESC line, which was previously shown to be pluripotent (eg, [66,67]).

Pax7wt1, Pax7wt2, Pax7ko1, Pax7ko2, and D3 ESCs were cultured under conditions that supported pluripotency and self-renewal, that is, in a medium containing LIF, and then were processed for mRNA analysis or immunolocalization of pluripotency markers. All analyzed ESCs expressed Sox2 and Nanog, as shown by qPCR (Fig. 1B) and immunodetection (Fig. 1C). In all tested cell lines, Nanog was present in the nuclei of ESCs (Fig. 1C). Analyses of cell colonies revealed that in the D3 line, $\sim 86 \%$ of cells expressed Nanog, compared with 56.2\% in Pax7wt1, 53.8\% in Pax7wt2, 59\% in Pax7ko1, and $80.7 \%$ in Pax7ko2 (Fig. 1E). Similarly, Oct-4 was detectable in the nuclei of all of cell lines analyzed, as $92 \%$ of D3 cells, $88 \%$ of Pax $7 \mathrm{wt} 1$ cells, $85 \%$ of Pax $7 \mathrm{wt} 2$ cells, $90 \%$ of Pax7ko1 cells, and $92 \%$ of Pax7ko2 cells expressed this factor (Fig. 1D, F). Flow cytometry analysis showed that ESCs also expressed SSEA-1 antigen (D3, 68\%; Pax7wt1, 81.9\%; Pax7wt2, 53.8\%; Pax7ko1, 80.7\%; and Pax7ko2, 59\%; Fig. 1G).

Next, we compared the ability of Pax7wt and Pax7ko ESC lines to differentiate into tissues that originated from the three germ layers. To do so, we tested whether they could differentiate in vivo (ie, form teratomas) or in vitro (ie, in EBs). In both settings, spatiotemporal interactions between differentiating cells allowed for the generation of ectodermal, endodermal, and mesodermal derivatives (reviewed in Grabowska et al. [17]). In vivo assays showed that all cell lines analyzedPax7wt1, Pax7wt2, Pax7ko1, and Pax7ko2 cells-could form complex teratomas. Histological analyses revealed that many tissues could be generated, including ectodermal squamous epithelium (Fig. 1H, a-d), endodermal ciliated epithelia (Fig. 1H, h) or secretory epithelium (Fig. 1H, e-g), as well as tissues of mesodermal origin, such as connective tissues, including cartilage (Fig. 1H, i-1).

In vitro differentiation of ESCs could be induced by the formation of EBs (Fig. 2A). In brief, for the first 2 days, all EBs were cultured in media supplemented with 15\% FBS. Starting from 13 day of culture, EBs were cultured in media in which the concentration of FBS was reduced. The choice of such conditions was based on previously published observations that suggested that deprivation of certain factors present in FBS could prevent proliferation and enhance differentiation (reviewed in Salani et al. [68]). Under such conditions, Pax7wt1, Pax7wt2, Pax7ko1, Pax7ko2, and D3 ESCs expressed the ectodermal marker Pax6, the endodermal marker Foxa2, and the mesodermal marker Brachyury ( $T$ ), as indicated by qPCR analyses (Fig. 2B). The ability of the ESCs that we tested to differentiate into cardiomyocytes was confirmed based on a protocol designed by Wobus et al. (Fig. 2C). All ESC lines that we tested synthesized cardiac troponin T, as shown by immunolocalization (Fig. 2D). Thus, we established that the ESCs that we derived, like D3 cells, are pluripotent, as they could differentiate in vitro and in vivo into cells of ectodermal, endodermal, and mesodermal origin.

\section{Myogenic differentiation of Pax7wt and Pax7ko ESCs}

Subsequent analyses of Pax $7 \mathrm{wt}$ and Pax7ko ESCs focused on the ability of these cells to differentiate into skeletal myoblasts. To induce myogenic differentiation in vitro, ESCs were subjected to a protocol involving the generation of EBs and EB outgrowths (Fig. 3A). According to this experimental scheme, starting from 13 day of culture, EBs were placed in media characterized by a reduced concentration of FBS [68]. From days 2 to 5, to support myogenic differentiation, the culture medium was supplemented with 
A
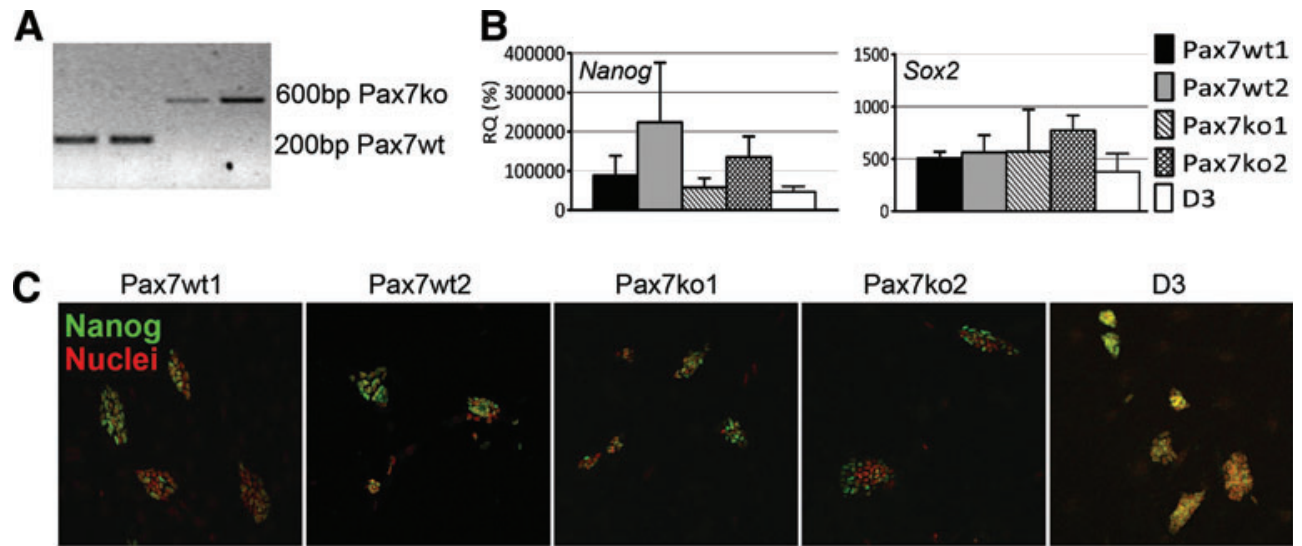

Pax7ko1

Pax7ko2

D3
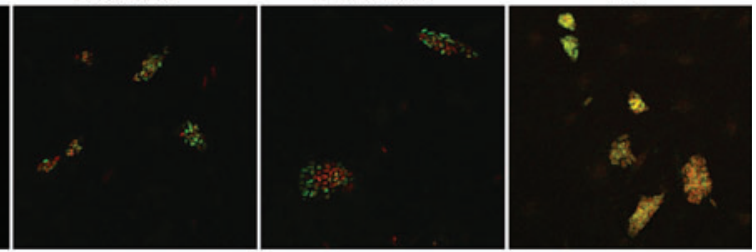

D Oct-4

Nuclei.
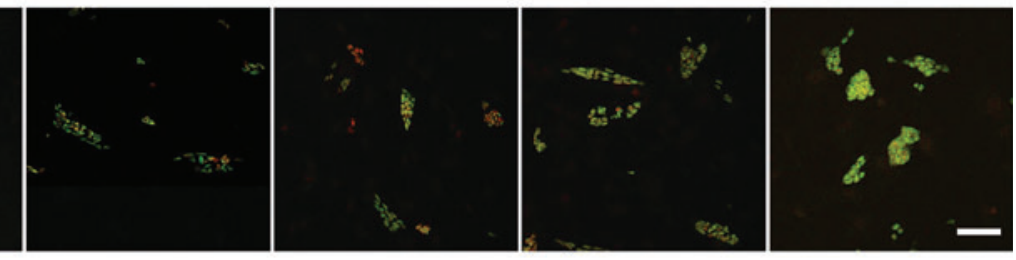

E
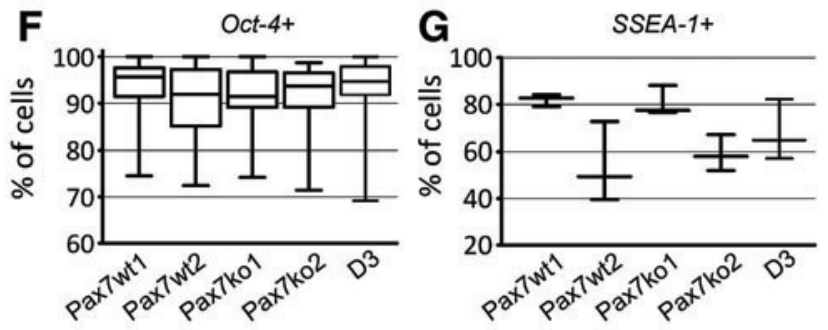

H

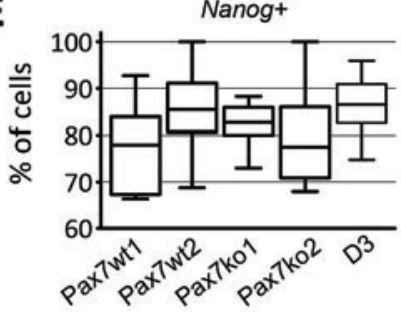

Pax7wt2

Pax7ko1

Pax7ko2
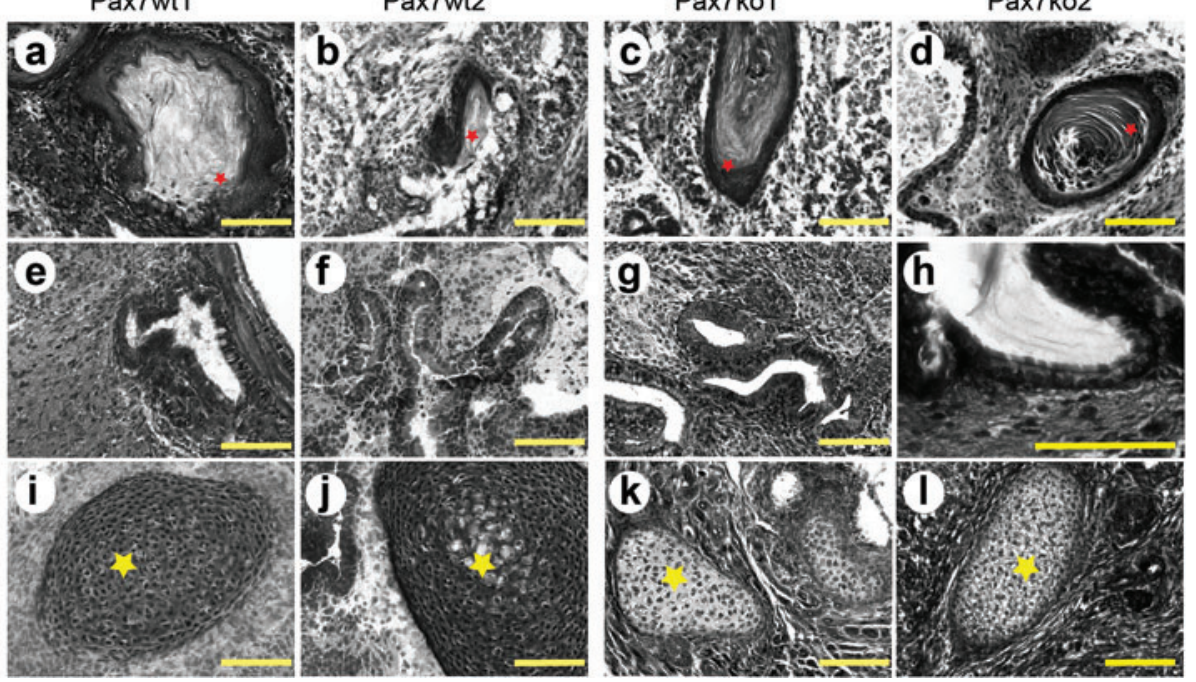

FIG. 1. Characteristics of Pax7wt, Pax7ko, and D3 embryonic stem cells (ESCs). (A) Genotyping of Pax7wt and Pax7ko ESCs. Representative agarose gel images with PCR products $\sim 200 \mathrm{bp}$ representing the wild-type allele and $\sim 600 \mathrm{bp}$ representing the mutant allele. (B) qRT-PCR analysis of Nanog and Sox2 mRNA transcript levels in Pax7wt, Pax7ko, and D3 ESCs. (C) Localization of Nanog (green) and nuclei (red) in undifferentiated Pax7wt, Pax7ko, and D3 ESC colonies growing on a mouse embryonic fibroblast (MEF) feeder layer (out of focus). (D) Localization of Oct-4 (green) and nuclei (red) in undifferentiated Pax7wt, Pax7ko, and D3 ESCs that formed colonies grown on an MEF feeder layer (out of focus); bar, $50 \mu \mathrm{m}$. (E) Proportion of Nanog-expressing cells detected by immunolocalization. (F) Proportion of Oct-4-expressing cells detected by immunolocalization. (G) Proportion of SSEA-1-expressing cells detected by flow cytometry. (E-G) The bottom and top of the box represent the first and third quartiles, band inside the box or band alone represents the second quartile (the median), and the ends of the whiskers represent the minimum and maximum of all of the data. (H) Histological analysis of teratomas derived from Pax7wt and Pax7ko ESCs; (a-d), ectodermal squamous epithelium (red stars); (e-h), endodermal epithelia; and (i-l), mesodermal cartilage (yellow star). Gomori's trichrome staining was used in (a-e, k-l); Masson's trichrome staining was used in $(\mathbf{g}-\mathbf{h})$; and hematoxylin and eosin staining was used in $(\mathbf{f}, \mathbf{i}, \mathbf{j}) ;$ bar, $100 \mu \mathrm{m}$. The mRNA transcript levels measured by qPCR as CT values were normalized to the CT value of actin; data are represented as a percentage of expression observed in a mouse embryo at day 13.5 of development. Color images available online at www.liebertpub.com/scd 
A

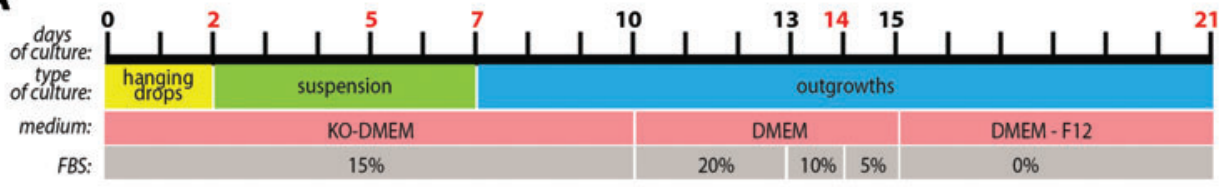

B
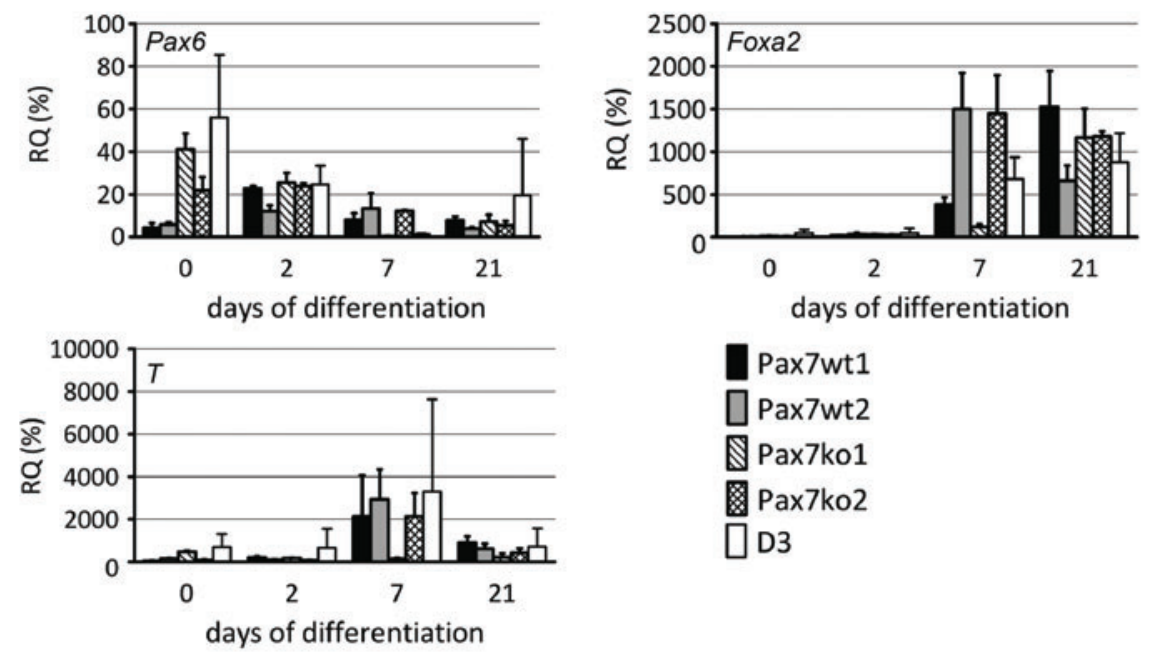

Pax7wt1

口Pax7wt2

$\mathbb{N}$ Pax7ko1

图Pax7ko2

$\square \mathrm{D} 3$

C
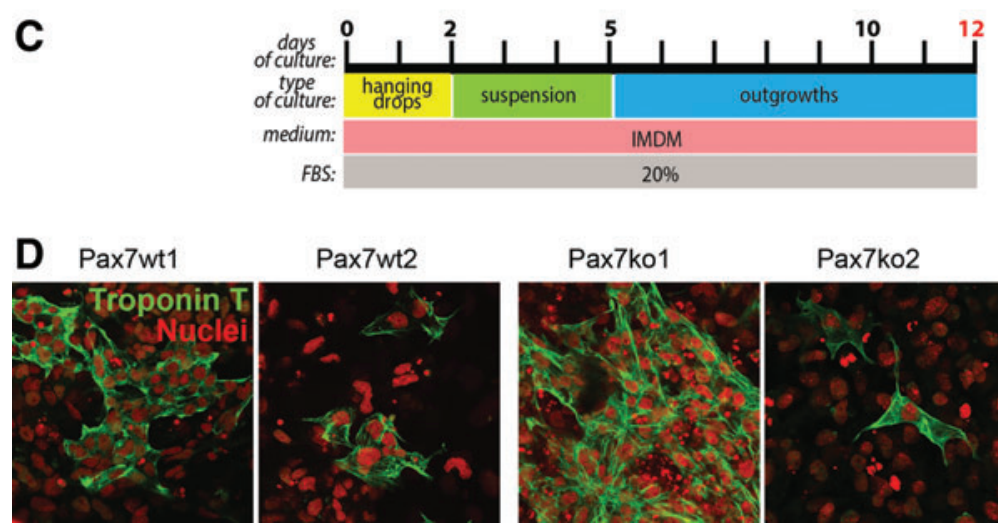

Pax7wt2

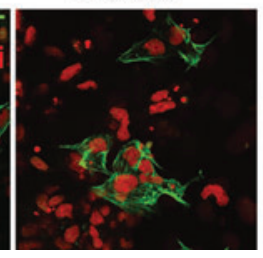

Pax7ko1

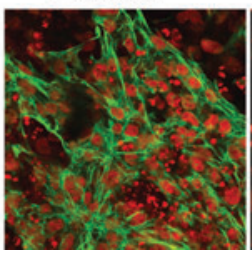

Pax7ko2

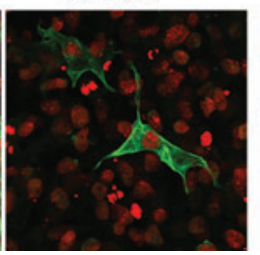

D3

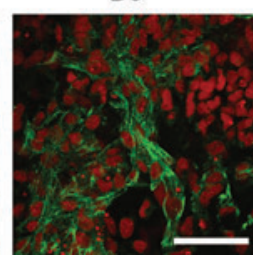

FIG. 2. Analysis of the differentiation of Pax7wt, Pax7ko, and D3 ESCs. (A) This schematic diagram shows the protocol used to induce the differentiation of ESCs. (B) qRT-PCR analysis of Pax6, Foxa2, and $T$ (Brachyury) mRNA transcript levels in undifferentiated ESCs at day 0 , embryoid bodies (EBs) at days 2 and 7, and EB outgrowths at day 21 of in vitro culture. (C) This schematic diagram shows the protocol used to induce the differentiation of ESCs into cardiomyocytes. (D) Localization of cardiac troponin $\mathrm{T}$ (green) and nuclei (red) in Pax7wt, Pax7ko, and D3 ESCs at 12 days of in vitro culture; bar $50 \mu \mathrm{m}$. Data obtained by qPCR analysis of mRNA transcript levels are presented as CT values normalized against those of actin; data represent the percentage of expression observed in mouse embryos at day 13.5 of development. Color images available online at www.liebert pub.com/scd
RA and a combination of insulin, transferrin, and selenium (ITS) $[56,58,69]$.

In preliminary experiments, we confirmed that ESCs cultured under conditions that supported pluripotency did not express significant levels of transcripts that encoded myogenic markers, such as Pax3, or MRFs, such as MyoD1 or Myog. The levels of mRNA transcripts that encoded the abovementioned factors were much lower than those detected in day 13.5 mouse embryos, which served as a positive control (Fig. 3B). Using sqRT-PCR, we also showed that Pax7wt ESCs could induce Pax7, which became detectable at days 7 and 14 of differentiation (Fig 3C).

Next, we analyzed the expression of genes that regulate pluripotency and differentiation by the microarray technique. For these analyses, we used Pax7wt1 and Pax7ko1 ESCs. We chose these two cell lines because they induced high levels of the mesodermal marker $T$ (Fig. 3D) and were characterized by a high efficiency of myoblast formation (based on MyHC and MyoD expression, see Fig. 4), compared with two other cell lines differentiated in the presence of RA and ITS (Fig. 3A). For each genotype and time point (days 0, 7, and 21), we analyzed three independent samples. ANOVA al- lowed us to create lists of similarly expressed genes and also significantly up- and downregulated genes that differed between Pax7wt1 and Pax7ko1 ESCs at day 0 (undifferentiated) and at days 7 and 21 of differentiation (Supplementary Tables S1-S6; Supplementary Data are available online at www.liebertpub.com/scd). The transcriptomes of undifferentiated ESCs showed 442 up- or downregulated genes that differed between Pax 7wt and Pax 7ko cells. Those differences in gene expression become more pronounced as ESC differentiation progressed, with 805 differentially expressed genes at day 7 and 1988 differentially expressed genes at day 21 (Fig. 3E and Supplementary Tables S1-S6).

In both Pax7wt1 and Pax7ko1 ESCs, the expression of mRNAs that encoded the pluripotency markers Sox2, Nanog, and Utfl was downregulated by day 21 of differentiation (Fig. 3F). In addition, expression levels of $P d g f r \alpha$, a marker of the paraxial mesoderm [70], increased and its levels were only slightly lower in Pax7ko1, compared to Pax7wt1. The mRNA transcript levels of $F g f r l$, which encodes a factor known to be involved in mesoderm formation and myogenic differentiation [71], were higher in Pax7ko1 (Fig. 3F). Thus, in both of the cell lines that we analyzed, mesodermal 


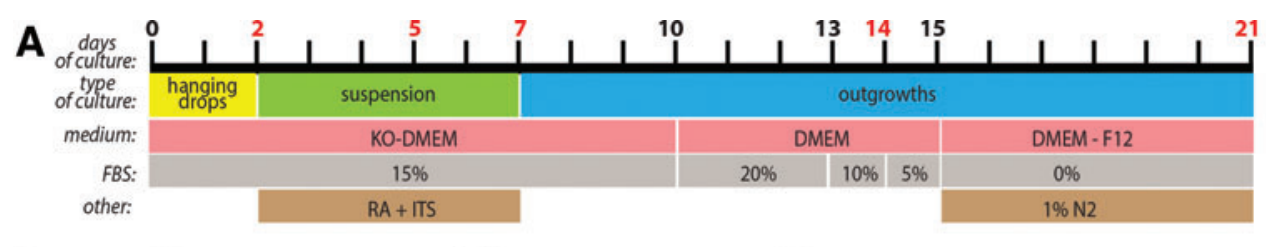

B
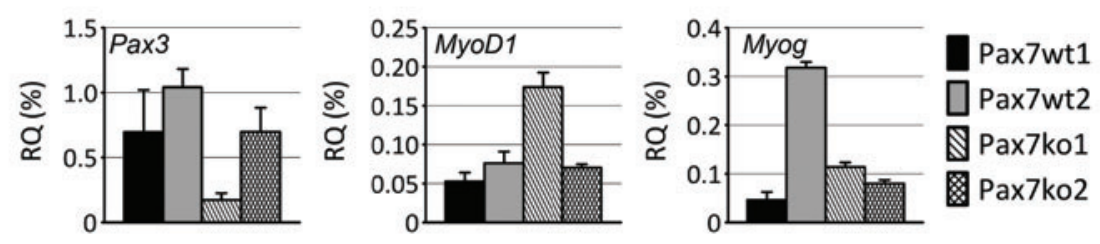

C
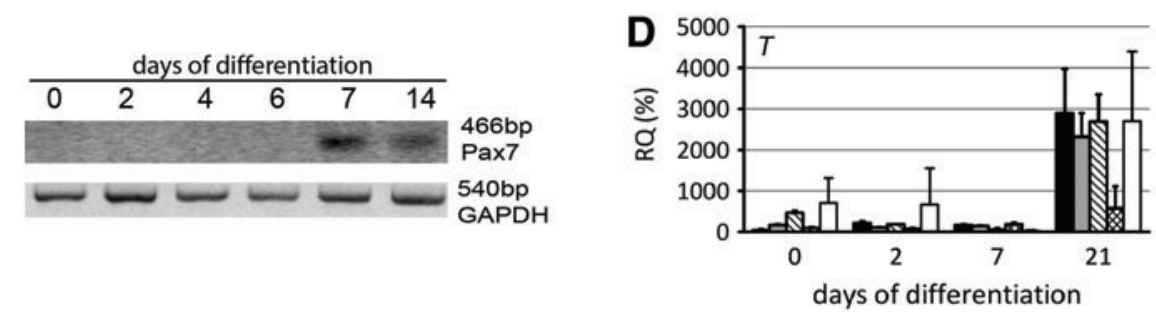

E
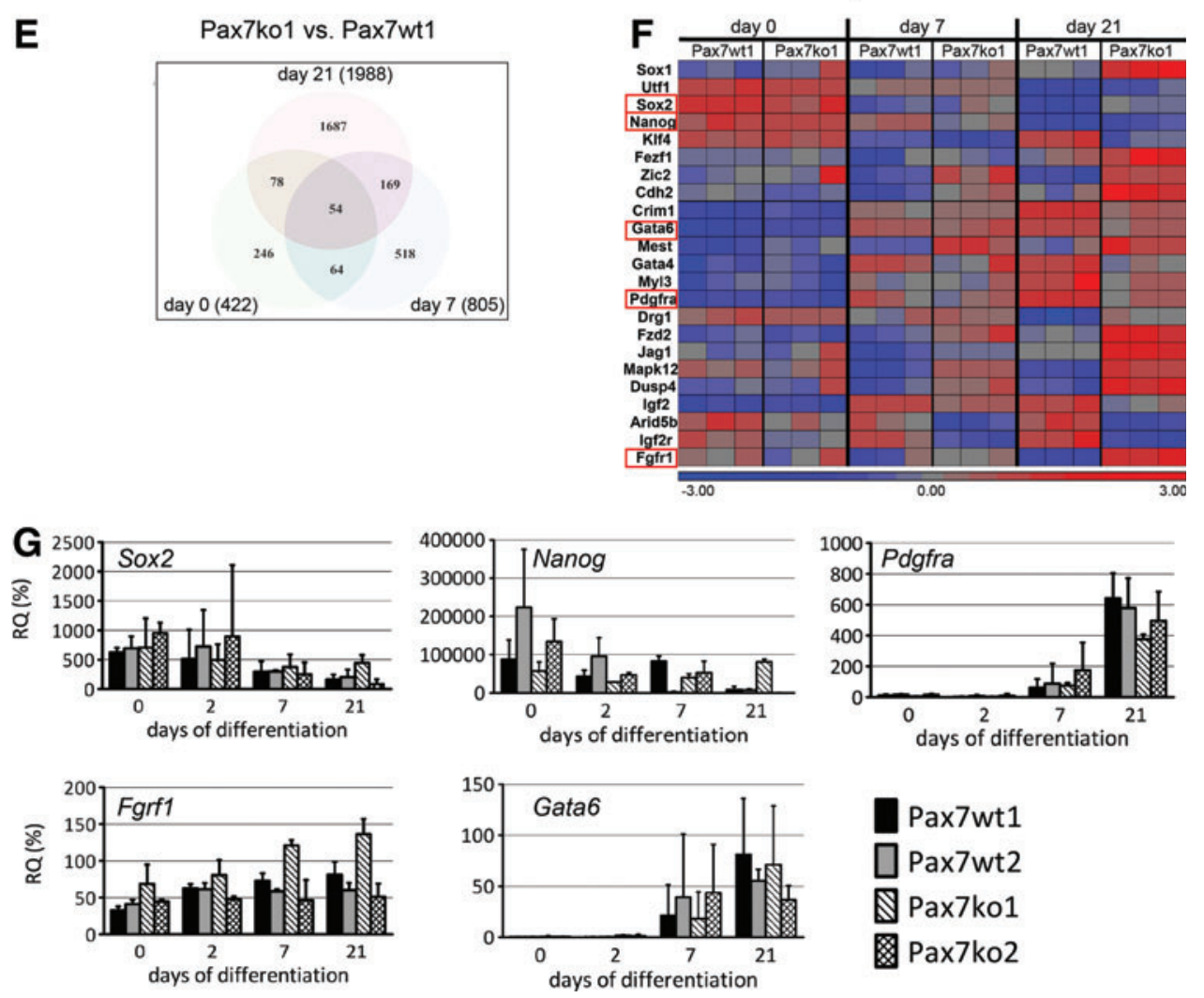

FIG. 3. Analysis of the expression of pluripotency- and differentiation-associated genes in Pax7wt and Pax7ko ESCs. (A) This schematic diagram shows the protocol used to induce the myogenic differentiation of ESCs. (B) qRT-PCR analysis of Pax3, MyoD, and Myog mRNA transcript levels in undifferentiated ESCs cultured under pluripotency supporting conditions. (C) Semi-quantitative RT-PCR analysis of Pax7 expression in undifferentiated Pax7wt1 ESCs at day 0, in differentiating EBs at days 2, 4, 6, and 7, and in EB outgrowths at day 14 of culture. Representative agarose gel images with PCR products $\sim 466$ bp representing Pax7 and $\sim 540$ bp representing GAPDH. (D) qRT-PCR analysis of $T$ (Brachyury) expression in undifferentiated ESCs at day 0, in EBs at days 2 and 7, and in EB outgrowths at day 21 of in vitro culture. (E) The Venn graphs show the number of transcripts for which expression is common or different for Pax 7wt1 and Pax 7ko1 ESCs analyzed at various time points of differentiation. Colors: green, undifferentiated ESCs (day 0); blue, EBs (day 7); pink, EB outgrowths (day 21). Significantly differentially expressed genes were identified using analysis of variance (ANOVA). (F) Analysis of the expression levels of transcripts that encoded pluripotency- and differentiation-associated proteins; each group included triplicate measurements. Blue color indicates low expression and red color indicates high expression levels of transcripts. All genes shown were selected from the complete list presented in Supplementary Tables S1-S6. (G) qPCR analysis of Sox2, Nanog, Pdgfra, Fgfrl, and Gata6 mRNA transcript levels. Data obtained using qPCR to assess mRNA transcript levels are shown as CT values, which were normalized against those of actin; data are represented as the percentage of expression observed in mouse embryos at day 13.5 of development. Color images available online at www.liebertpub.com/scd 
precursors had formed, as was also indicated by analyses of $T$ (Brachyury) expression (Fig. 3D). Next, we found that Pax7wt1 and Pax7ko1 ESCs showed increased expression of differentiation-associated genes, such as neuroectodermal Soxl [72] or cardiac and skeletal myogenesis-associated Gata4, Gata6 [73], and Myl3 [74] (Fig. 3F). The expression levels of these and other transcripts were higher in Pax $7 \mathrm{kol}$ compared with Pax7wt1 ESCs (Fig. 3F). Microarray results for selected genes, Nanog, Sox2, Pdgfra, Fgfrl, and Gata6, were verified by qRT-PCR analyses of mRNA isolated from cells of each of the four ESC lines (Pax7wt1, Pax7wt, Pax7ko1, and Pax7ko2) that were induced to undergo differentiation in additional independent experiments (Fig. 3G). For almost all of the genes analyzed, except for Fgfrl, changes in transcript levels reflected the results that we obtained from microarray analyses.

The expression of factors critical for the specification and differentiation of skeletal myoblasts, such as Pax3, MyoD1, Myog, Myf5, Meg3, and Id2, increased during ESC differentiation, but was not significantly different between Pax7wt1 and Pax7ko1 ESCs (Fig. 4A). Levels of Pax3, MyoD, myogenin (Myog) (Fig. 4B), and other myoblastspecific factors, such as M-cadherin ( $C d h 15$, data not shown) and MyHC (Myh7), were verified in the four ESC lines by qPCR (Fig. 4D). The expression levels of these genes were low in undifferentiated ESCs and in EBs at day 2 of differentiation of all analyzed cell lines, but then increased at days 7 or 21 . Interestingly, qPCR analysis of $P a x 3$ expression differed from the microarray findings, as it showed that $P a x 3$ was expressed at day 7 , whereas microarrays indicated that this gene was induced later, at approximately day 21 of differentiation. This discrepancy most likely resulted from subtle changes in the culture conditions (mRNA for these analyzes was obtained from independent ESC cultures), which in case of some sensitive genes might have altered expression levels. The levels of MyoDl and Myog were upregulated at day 21 (Fig. 4A, B). In addition to Pax3 and MRFs, levels of transcripts that encoded other regulators of myogenesis, such as $B M P 4$ or $I d 2$, as well as structural and adhesion proteins, such as myosins, laminin $\alpha 1$, and N-CAM, increased during differentiation, but were comparable between Pax7wt1 and Pax7ko1 ESCs (Fig. 4A).

At 21 days of culture, EB outgrowths of the four ESC lines (Pax7wt1, Pax7wt2, Pax7ko1, and Pax7ko2) were similar to those of D3 ESCs (data not shown), which contained cells that synthesized MyHC, a late differentiation marker of myoblasts. In all Pax7wt and Pax7ko cultures that we analyzed, MyHC expression was clearly detectable (Fig. 4C). MyHC-positive outgrowths contained various numbers of myoblasts and multinucleated myotubes, indicating that the progeny of the ESCs that we tested could reach advanced stages of myogenic differentiation. The mean numbers of MyHC-positive cells per outgrowth culture, calculated from at least three independent analyzes, were as follows: Pax7wt1, 87; Pax7wt2, 8; Pax7ko1, 156; and Pax7ko2, 4 (minima, maxima, and median values are shown in Fig. 4D). Next, we analyzed the expression of the transcription factor MyoD in the two ESC lines that were characterized by the highest number of MyHC-expressing myoblasts and myotubes, Pax7wt1 and Pax7ko1 (Fig. 4F). In Pax7wt1 EB outgrowths, we identified $\sim 171$ cells per outgrowth culture that expressed this transcription factor. Interestingly, Pax 7ko1 EB outgrowths were characterized by a higher number of MyoDpositive cells, as they contained $\sim 311$ MyoD-positive cells (minima, maxima, and median values are shown in Fig. 4E).

We also assessed whether myoblasts and myotubes formed by the ESCs that we analyzed were primary (embryonic) or secondary (fetal) myoblasts. To verify this, we analyzed the expression of mRNA transcripts that encoded $M y h 7, N f i x$, and Eno3 in undifferentiated ESCs and at days 2, 7, and 21 of differentiation (Fig. 4D). The slow isoform of myosin heavy chain $(M y h 7)$ is expressed in embryonic myofibers [75]. The product of the gene Nfix controls the switch between embryonic and fetal myogenesis. Expression of Nfix occurs in fetal myoblasts and induces the expression of genes that are characteristic of fetal myofibers, such as $\mathrm{Ckm}$ that encodes creatinine kinase or Eno3 that encodes beta-enolase [76]. Our analysis showed that by day 21 of differentiation, both Pax7wt and Pax7ko ESCs induced $M y h 7$ expression. At day 21 of differentiation, Nfix expression was only higher in Pax7ko1 ESCs compared with the levels observed in the other three cell lines at days 0, 2, and 7. Levels of Eno3 transcripts, which encode a factor characteristic of fetal myoblasts, were comparable in all analyzed samples, regardless of the stage of differentiation or genotype (Fig. 3D). Thus, the myogenic differentiation of ESCs leads to the generation of myotubes with embryonic characteristics, indicated by $M y h 7$ expression, and precursors of fetal ones, indicated by Nfix expression.

Microarray analyses of ESCs also showed that the levels of transcripts that encoded proteins associated with chromatin organization or nuclear trafficking and the regulation of transcription or translation were higher in differentiating Pax7ko1 compared with Pax7wt ESCs. Among the genes characterized by higher expression levels in Pax $7 \mathrm{kol}$ cells were importins, histones, methyltransferases, ribosomal proteins, and cell cycle regulating factors (Supplementary Fig. S1 and Supplementary Tables S1-S6). However, these differences mentioned earlier did not impact the potential of these ESCs to undergo myogenic differentiation.

\section{MicroRNAs in Pax7wt and Pax7ko ESCs}

In addition to analyses of mRNA transcript levels, we also assessed the expression levels of microRNAs (miRNAs). We chose to analyze those miRNAs known to be involved in stem cell differentiation or the regulation of myogenesis in two of the ESC lines, Pax 7wt1 and Pax7ko1, cultured under myogenic differentiation-inducing conditions (Fig. 3A). For each analysis, we used RNA isolated from cells that were cultured during three independent experiments.

In the developing mouse embryo, Let7 is synthesized in the endoderm and mesoderm, but not the ectoderm [77]. An ESC-specific miRNA, miR294, has been linked to cell cycle regulation and is known to be downregulated throughout differentiation [78,79]. Consistently, we observed an increase in Let7 expression in differentiating ESCs that was correlated with a reduction in the expression levels of $m i R 294$ (Fig. 5). Interestingly, at day 14 of differentiation, the EB outgrowth stage, Let7 expression was found to be much higher in Pax7ko1 than in Pax7wt1 ESCs. A similar expression pattern has been reported for miR145a, a miRNA associated with mesodermal differentiation of ESCs [80]. Furthermore, $m i R 181$ has been shown to be involved in 
A

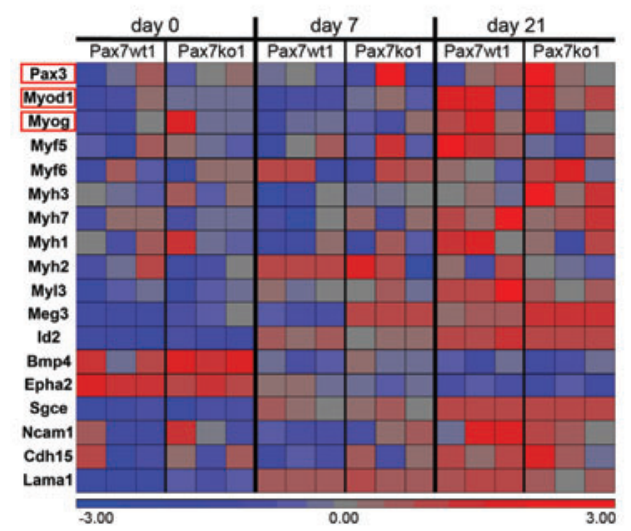

B
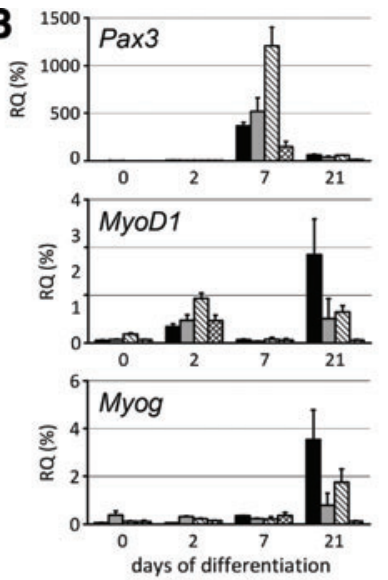

Pax7wt1

DPax7wt2

$\mathbb{Q}$ Pax7ko1

Pax7ko2

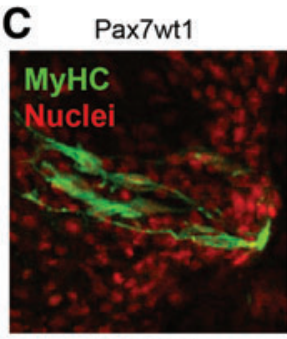

Pax7ko1
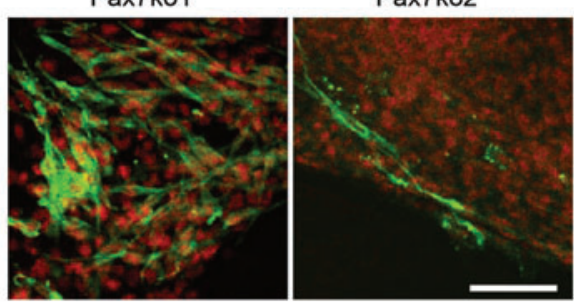

Pax7wt2

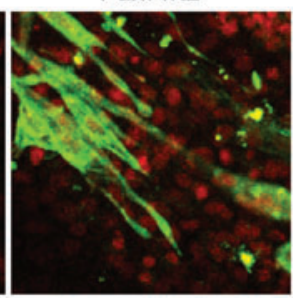

Pax7ko2

G

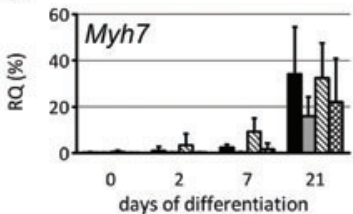

D

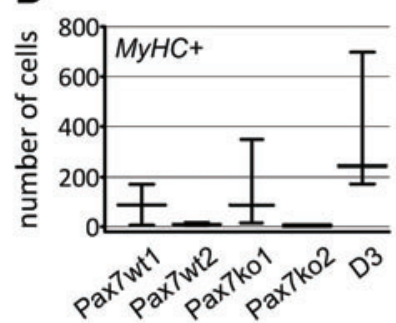

E

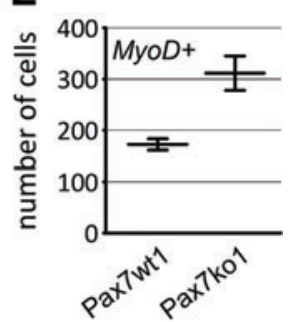

$\mathbf{F}$
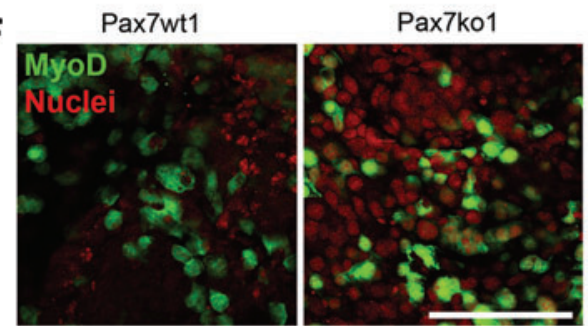

FIG. 4. Analysis of myogenic differentiation in Pax7wt and Pax7ko ESCs. (A) Analysis of the expression levels of transcripts that encoded myogenesis-associated genes in Pax7wt1 and Pax7ko1 ESCs; triplicate measurements were obtained for each group. Blue color indicates low and red color indicates high expression levels of mRNA transcripts. The genes shown were selected from the lists presented in Supplementary Tables S1-S6. (B) Analysis of Pax3, MyoD, and Myog expression by qPCR in undifferentiated ESCs at day 0, in EBs at days 2 and 7, and in EB outgrowths at day 21. (C) EB outgrowths analyzed at day 21 of culture. Localization of MyHC (green) and nuclei (red); bar, $50 \mu \mathrm{m}$. (D) The number of MyHC-expressing cells detected by immunolocalization. (E) The number of MyoD-expressing cells detected by immunolocalization. (D, E) The band represents the second quartile (the median) and the ends of the whiskers represent the minimum and maximum of all of the data. (F) EB outgrowths were analyzed at day 21 of culture. Localization of MyoD (green) and nuclei (red); bar, $100 \mu \mathrm{m}$. (G) Analysis of Myh7, Nfix, and Eno3 expression by qPCR in undifferentiated ESCs at day 0, in EBs at days 2 and 7, and in EB outgrowths at day 21. Data obtained by qPCR analysis of mRNA transcript expression levels are shown as CT values, which were normalized against those of actin; data are represented as the percentage of expression observed in mouse embryos at day 13.5 of development. Color images available online at www.liebertpub.com/scd

myogenic differentiation by inhibiting the expression of Hoxa11, which results in blocking MyoD [81]. Similarly, at day 14 of differentiation, the expression of this miRNA was higher in Pax7ko1 than in Pax7wt1 cells.

Additional miRNAs, $m i R 1, m i R 133 a$, and $m i R 133 b$, also affect the myogenic differentiation of skeletal muscle and heart tissue. Specifically, $m i R 1$ promotes myogenesis by inhibiting the expression of Hdac4, which can block Mef2 [82]. It also impacts expression of Pax7 [24]. The miR133a reduces the transcript levels of cyclin D1 (Ccnd1) and serum responsive factor $(S r f)$, resulting in a reduction in the proliferation capacity of myoblasts [82,83]. The miR133b 

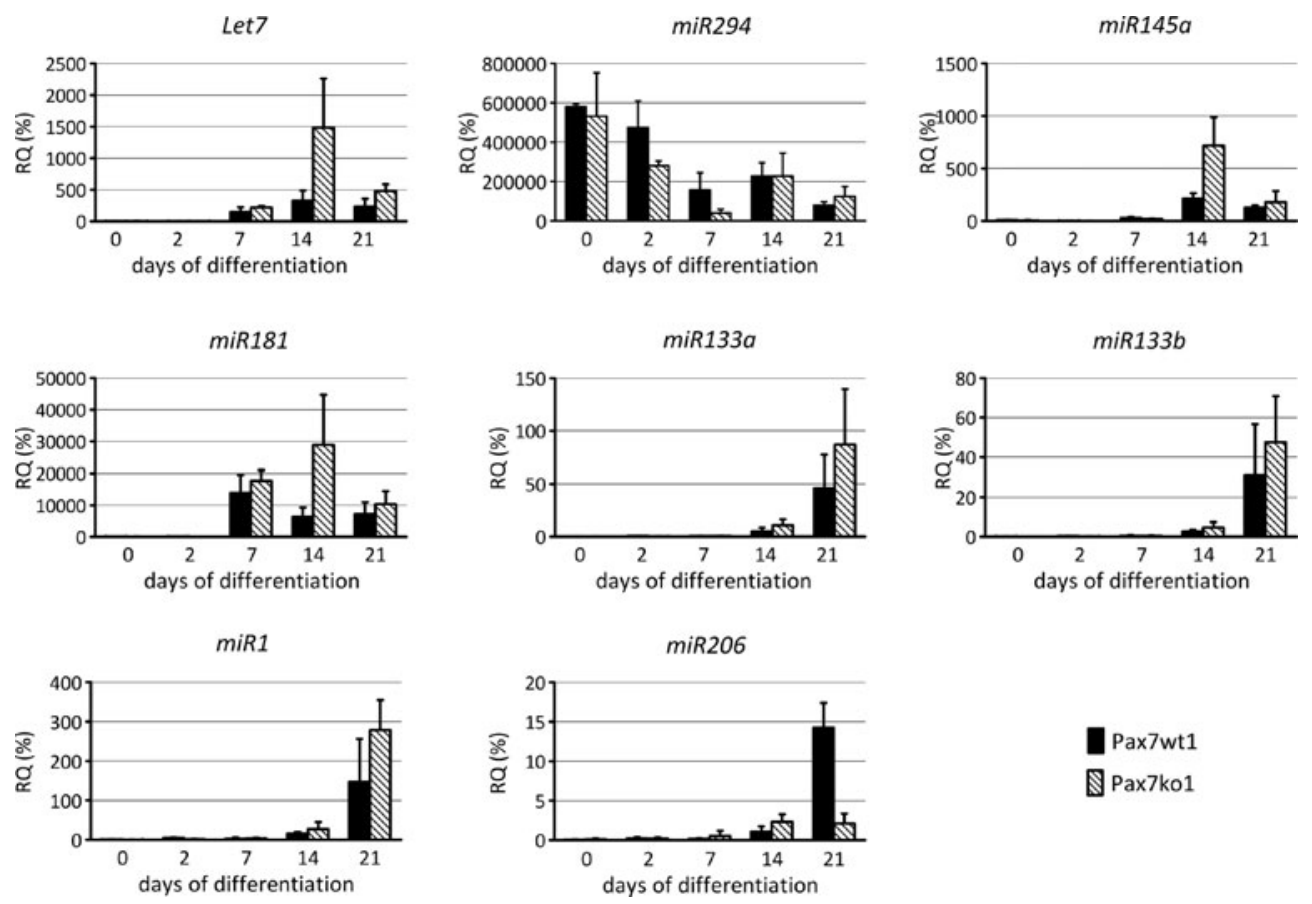

Pax7wt1
$\mathbb{Q}$ Pax7ko1

FIG. 5. Analysis of microRNAs expression in pluripotent and differentiating Pax7wt and Pax7ko ESCs. Levels of Let7a, miR294, miR145a, miR181, mir133a, miR133b, miR1, and miR206 expression were analyzed by qPCR in undifferentiated ESCs at day 0, in EBs at days 2 and 7, and in EB outgrowths at days 14 and 21. Data obtained for the expression levels of microRNAs as CT values were normalized against those of $U 6$ snRNA; data are represented as the percentage of expression observed in mouse embryo at day 13.5 of development.

downregulates Fscnl expression, which encodes a protein that is involved in the proper organization of actin cytoskeleton [84]. By day 21 of culture, the expression levels of $m i R 1, m i R 133 a$, and miR133b were similarly increased in both Pax7wt1 and Pax7ko1 cells. Interestingly, miR206, which has been shown to regulate myogenic differentiation and to downregulate $\operatorname{Pax} 7$ mRNA levels [25], was upregulated in Pax7wt1, but not Pax7ko1 cells. Thus, in the absence of a functional Pax7 gene, the expression of miRNAs that regulate mesoderm induction, such as Let7 and miR145a, as well as a miRNA that is involved in the regulation of myogenic differentiation, such as miR181, was clearly increased at 14 days of differentiation.

In summary, analyses of the levels of myogenic transcripts and the in vitro differentiation of Pax7wt and Pax 7ko ESCs revealed that irrespective of genotype, these cells could undergo myogenic differentiation.

\section{Discussion}

Embryonic myogenesis covers the formation of different myoblast populations. First, muscle fibers are formed in mouse embryo between E10.5-12.5 as a result of the fusion of cells known as embryonic myoblasts. Next, a wave of myogenic differentiation, that is, secondary myogenesis, occurs between E14.5-17.5 and involves fetal myoblasts formation $[12,85]$. Satellite cells can be identified from E16.5. Both paired box transcription factors, Pax3 and Pax7, are expressed in myoblasts formed during embryogenesis and also in satellite cells. However, in the majority of skeletal muscles, only a subpopulation of satellite cells express Pax3 $[6,32,86,87]$. Fetal myoblasts predominantly express Pax7
[75,88]. Surprisingly, the absence of functional Pax7 does not affect embryonic or fetal myogenesis, but does alter the function of adult satellite cells, suggesting that different mechanisms may regulate these processes [6,14,31]. During embryonic myogenesis, and also in satellite cells, Pax7 regulates the expression of MRFs. Furthermore, Pax7 downregulation allows for myoblast differentiation and the formation of myotubes and muscle fibers (eg, [9-13]).

Many lines of evidence indicate that proteins that control embryonic myogenesis, that is, MRFs, play a pivotal role during the myogenic differentiation of ESCs (for a review, see Grabowska et al. [17]). In pioneering experiments, overexpression of MyoDl induced the synthesis of skeletal muscle-specific proteins and led to the myogenic differentiation of P19 ECCs (embryonic carcinoma cells) or ESCs into myotubes or myoblasts [89-92]. The success rate of these experiments depended greatly on the culture conditions. For example, the expression of MyoD1 in monolayer-cultured mouse ESCs resulted in the synthesis of myogenin and myosin light chain 2, but was not sufficient to promote myotube formation [89]. However, when stem cells were differentiated into EBs or EB outgrowths in which the synthesis of MyoD1 and $\operatorname{Pax} 3$ were induced, myoblast derivation was more efficient [93]. Extensive work carried out by the Perlingeiro group established the critical role of exogenously introduced Pax3 and Pax7 in driving the myogenic differentiation of ESCs and iPSCs [94-98]. Importantly, none of these experiments directly verified whether the role of $\mathrm{Pax} 7$ in regulating the myogenic differentiation of ESCs was similar to what occurs during embryonic myogenesis.

To test whether Pax7 drives the myogenic differentiation of ESCs, we derived cells lacking a functional $\operatorname{Pax} 7$ gene. 
Interestingly, such cells did not manifest any dramatic phenotype when cultured in vitro or when induced to differentiate into teratomas in vivo. All of the ESC lines that we generated were pluripotent. The in vitro culture and differentiation in EBs resulted in the expression of ectodermal, endodermal, and mesodermal markers, as revealed by qPCR and microarray analyses. Using the protocol that has been previously established and tested [59,99], we have shown herein that the ESCs differentiated into cells such as cardiomyocytes. Teratomas generated from Pax7wt and Pax7ko ESCs formed complex tumors that were composed of various types of epithelia and tissues of ectodermal, endodermal, and, importantly, mesodermal origins, such as connective tissue and cartilage. Thus, these cells did not differ in their ability to differentiate from other ESCs tested previously.

Molecular analyzes showed that Pax7ko ESCs could undergo myogenic differentiation and initiate the expression of transcripts that encoded markers characteristic of developing myoblasts, such as Pax3, MyoD, myogenin, Myf5, M-cadherin, or MyHC. Interestingly, we did not observe significant differences in the levels of transcripts that encoded these genes compared with wild-type cells, even though the expression of some of these genes, such as MyoD or Myf5, were shown to be controlled by $\operatorname{Pax} 7[11,20,21]$. Other studies have established that the absence of functional Pax7 did not affect the expression of myogenic factors, such as Pax3 [88]. Importantly, all of the ESCs that we tested, irrespective of genotype, could form MyHC and MyoD expressing myocytes and multinucleated myotubes. In the current study, we also established that the absence of functional Pax 7 did not affect the expression of Nfix in differentiating ESCs, indicating that the generation of fetal myoblast precursors might be Pax7 independent. Our results, however, do not establish whether the function of Pax7 in differentiating ESCs might be redundant with those of other factors. They also do not contradict previous data showing that $\operatorname{Pax} 7$ is involved in secondary myotube development and satellite cell specification, as well as their maintenance during postnatal muscle growth and regeneration $[4,39,100]$.

Most of the microRNAs that we analyzed showed a comparable pattern of expression in Pax7wt and Pax7ko ESCs. However, at day 14 of culture, stronger upregulation of three differentiation associated factors-Let7, miR145a, and miR181-was observed in Pax7ko ESCs. This finding might suggest that cells lacking functional Pax7 are characterized by a prolonged initial step of differentiation. For example, miR181, also known to be involved in hematopoietic differentiation, becomes downregulated in wild-type cells. However, at day 14 of differentiation, its expression level remains higher in Pax7ko ESCs compared with wildtype ESCs, which corresponds with the expression pattern of mesoderm-specific microRNA [101]. Muscle-specific miRNAs, including miR1, miR133a, and miR133b [82], are similarly expressed in Pax7ko and Pax7wt ESCs. Pax7 has been shown to prevent $M y o D 1$ expression in satellite cells and C2C12 myoblasts [20] and the expression of miRl, miR133, and miR206 depends on MyoD and Myf5 [28]. The miRNAs miRl and miR206 act to repress Pax 7 and Pax3 during myogenic differentiation [24,102]. Thus, in the absence of Pax 7 activity, MyoD should be derepressed and the levels of miR206 increased. However, in myoblasts, Pax7 has also been shown to promote the expression of $M y f 5$ through interactions with histone methyltransferase [21]. The absence of functional $\operatorname{Pax} 7$ also affects miR206 expression - at day 21, expression levels of this microRNA were dramatically higher in Pax7wt cells compared with mutant cells. However, we did not detect increased expression of MyoDl transcripts in Pax7ko ESCs. Thus, the negative feedback loop involving Pax7, MyoD, and miR206 does not operate in the ESCs that we analyzed. Interestingly, miR206 inhibition promotes the proliferation of $\mathrm{C} 2 \mathrm{C} 12$ myoblasts [103], so its lower expression level in Pax7ko ESCs might be related to the higher expression of transcripts that encode proteins that positively regulate DNA replication and cell cycle, as indicated by microarray analysis. Finally, using microarray analysis and comparing the transcriptomes of Pax7wt and Pax7ko cell lines, we did not identify any differences in the expression of MRFs, which was confirmed by our qPCR results.

In summary, Pax 7 function is dispensable for the myogenic differentiation of mouse ESCs. In the absence of functional $\operatorname{Pax} 7$, the expression of MRFs and markers of both primary and secondary myofibers were detectable. Notably, as has been shown in previous reports, the myogenic potential of the cell lines that we analyzed differed. Some of them, such as Pax7wt1 and Pax7ko1, were more prone to differentiate into myoblasts than the Pax $7 \mathrm{wt} 2$ and Pax $7 \mathrm{ko} 2$ cells described herein, as well as other cell lines that we derived (data not shown). Many lines of evidence established that ESCs differ in their ability to differentiate into myoblasts. Rohwedel et al. showed that BLC6 ESCs were more prone to give rise to myoblasts than D3, B117, or J1 ESCs [104]. Various cell lines or cells that originated from the same ESC line, but were cultured in different laboratories, may differ as a result of different treatments or prolonged in vitro culture $[105,106]$. In addition, subclones that result from a single cell line have been shown to differ in the level of DNA methylation, which may markedly affect gene expression patterns [107]. Despite these observed differences between the ESCs that we analyzed, all of these cells could undergo myogenic differentiation, irrespective of Pax7 expression.

\section{Acknowledgments}

The authors thank Ilona Kalaszczynska for providing valuable advice on ESC derivation, Shahragim Tajbakhsh for the opportunity to learn techniques, including ESC differentiation, Ewelina Kiernozek for assistance with FACS analyses, Katarzyna Ilach for providing fantastic technical support, Maciej Czerwiec for offering technical support on confocal microscopy, and Jaroslaw Czyz for advice on cardiomyocyte differentiation. They also thank the reviewers for their encouraging criticism. This project was supported by a grant provided by the funds from the National Science Centre (Poland), grant N N302 125939 for 2010-2013.

\section{Author Disclosure Statement}

No author has a commercial association that might create a conflict of interest.

\section{References}

1. Mauro A. (1961). Satellite cell of skeletal muscle fibers. J Biophys Biochem Cytol 9:493-495. 
2. Moss FP and CP Leblond. (1971). Satellite cells as the source of nuclei in muscles of growing rats. Anat Rec 170:421-435.

3. Katz B. (1961). The terminations of the afferent nerve fibre in the muscle spindle of the frog. Philos Trans R Soc Lond B Biol Sci 243:221-240.

4. Yablonka-Reuveni Z. (2011). The skeletal muscle satellite cell: still young and fascinating at 50 . J Histochem Cytochem 59:1041-1059.

5. Scharner J and PS Zammit. (2011). The muscle satellite cell at 50: the formative years. Skelet Muscle 1:28.

6. Relaix F, D Montarras, S Zaffran, B Gayraud-Morel, D Rocancourt, S Tajbakhsh, A Mansouri, A Cumano and M Buckingham. (2006). Pax3 and Pax7 have distinct and overlapping functions in adult muscle progenitor cells. $\mathrm{J}$ Cell Biol 172:91-102.

7. Bober E, T Franz, HH Arnold, P Gruss and P Tremblay. (1994). Pax-3 is required for the development of limb muscles: a possible role for the migration of dermomyotomal muscle progenitor cells. Development 120:603-612.

8. Williams BA and CP Ordahl. (1994). Pax-3 expression in segmental mesoderm marks early stages in myogenic cell specification. Development 120:785-796.

9. Braun T, E Bober, MA Rudnicki, R Jaenisch and $\mathrm{HH}$ Arnold. (1994). MyoD expression marks the onset of skeletal myogenesis in Myf-5 mutant mice. Development 120: 3083-3092.

10. Tajbakhsh S, D Rocancourt, G Cossu and M Buckingham. (1997). Redefining the genetic hierarchies controlling skeletal myogenesis: Pax-3 and Myf-5 act upstream of MyoD. Cell 89:127-138.

11. Olguin HC, Z Yang, SJ Tapscott and BB Olwin. (2007). Reciprocal inhibition between Pax 7 and muscle regulatory factors modulates myogenic cell fate determination. J Cell Biol 177:769-779.

12. Relaix F, D Rocancourt, A Mansouri and M Buckingham. (2005). A Pax3/Pax7-dependent population of skeletal muscle progenitor cells. Nature 435:948-953.

13. Sassoon D, G Lyons, WE Wright, V Lin, A Lassar, H Weintraub and M Buckingham. (1989). Expression of two myogenic regulatory factors myogenin and MyoD1 during mouse embryogenesis. Nature 341:303-307.

14. Seale P, LA Sabourin, A Girgis-Gabardo, A Mansouri, P Gruss and MA Rudnicki. (2000). Pax7 is required for the specification of myogenic satellite cells. Cell 102:777-786.

15. Feldman JL and FE Stockdale. (1992). Temporal appearance of satellite cells during myogenesis. Dev Biol 153:217-226.

16. Horst D, C Sergi, G Mikuz, H Juergens and E Vorobyov. (2005). Comparative expression analysis of Pax3 and Pax7 during myogenesis in the mouse embryo. J Pathol 207:3-3.

17. Grabowska I, K Archacka, AM Czerwinska, M Krupa and MA Ciemerych. (2012). Mouse and human pluripotent stem cells and the means of their myogenic differentiation. Results Probl Cell Differ 55:321-356.

18. Relaix F, D Rocancourt, A Mansouri and M Buckingham. (2004). Divergent functions of murine Pax3 and Pax7 in limb muscle development. Genes Dev 18:1088-1105.

19. Kumar D, JL Shadrach, AJ Wagers and AB Lassar. (2009). Id3 is a direct transcriptional target of Pax7 in quiescent satellite cells. Mol Biol Cell 20:3170-3177.

20. Olguin HC and BB Olwin. (2004). Pax-7 up-regulation inhibits myogenesis and cell cycle progression in satellite cells: a potential mechanism for self-renewal. Dev Biol 275:375-388

21. McKinnell IW, J Ishibashi, F Le Grand, VG Punch, GC Addicks, JF Greenblatt, FJ Dilworth and MA Rudnicki. (2008). Pax 7 activates myogenic genes by recruitment of a histone methyltransferase complex. Nat Cell Biol 10:77-84.

22. Crist CG, D Montarras and M Buckingham. (2012). Muscle satellite cells are primed for myogenesis but maintain quiescence with sequestration of Myf5 mRNA targeted by microRNA-31 in mRNP granules. Cell Stem Cell 11: 118-126.

23. Crist CG, D Montarras, G Pallafacchina, D Rocancourt, A Cumano, SJ Conway and M Buckingham. (2009). Muscle stem cell behavior is modified by microRNA-27 regulation of Pax3 expression. Proc Natl Acad Sci U S A 106: 13383-13387.

24. Chen JF, YZ Tao, JA Li, ZL Deng, Z Yan, XA Xiao and DZ Wang. (2010). microRNA-1 and microRNA-206 regulate skeletal muscle satellite cell proliferation and differentiation by repressing Pax7. J Cell Biol 190:867-879.

25. Dey BK, J Gagan and A Dutta. (2011). miR-206 and -486 induce myoblast differentiation by downregulating Pax7. Mol Cell Biol 31:203-214.

26. Rao PK, RM Kumar, M Farkhondeh, S Baskerville and HF Lodish. (2006). Myogenic factors that regulate expression of muscle-specific microRNAs. Proc Natl Acad Sci U S A 103:8721-8726.

27. Liu N, AH Williams, Y Kim, J McAnally, S Bezprozvannaya, LB Sutherland, JA Richardson, R Bassel-Duby and EN Olson. (2007). An intragenic MEF2-dependent enhancer directs muscle-specific expression of microRNAs 1 and 133. Proc Natl Acad Sci U S A 104: 20844-20849.

28. Sweetman D, K Goljanek, T Rathjen, S Oustanina, T Braun, T Dalmay and A Munsterberg. (2008). Specific requirements of MRFs for the expression of muscle specific microRNAs, miR-1, miR-206 and miR-133. Dev Biol 321: 491-499.

29. Mansouri A, A Stoykova, M Torres and P Gruss. (1996). Dysgenesis of cephalic neural crest derivatives in Pax7-/mutant mice. Development 122:831-838.

30. Seale P, A Polesskaya and MA Rudnicki. (2003). Adult stem cell specification by Wnt signaling in muscle regeneration. Cell Cycle 2:418-419.

31. Oustanina S, G Hause and T Braun. (2004). Pax7 directs postnatal renewal and propagation of myogenic satellite cells but not their specification. EMBO J 23:3430-3439.

32. Kuang S, SB Charge, P Seale, M Huh and MA Rudnicki. (2006). Distinct roles for Pax7 and Pax3 in adult regenerative myogenesis. J Cell Biol 172:103-113.

33. Hutcheson DA, J Zhao, A Merrell, M Haldar and G Kardon. (2009). Embryonic and fetal limb myogenic cells are derived from developmentally distinct progenitors and have different requirements for beta-catenin. Genes Dev 23:997-1013.

34. Worl J, C Breuer and WL Neuhuber. (2009). Deletion of Pax7 changes the tunica muscularis of the mouse esophagus from an entirely striated into a mixed phenotype. Dev Dyn 238:864-874.

35. Lepper C, SJ Conway and CM Fan. (2009). Adult satellite cells and embryonic muscle progenitors have distinct genetic requirements. Nature 460:627-631.

36. Gunther S, J Kim, S Kostin, C Lepper, CM Fan and T Braun. (2013). Myf5-positive satellite cells contribute to 
Pax7-dependent long-term maintenance of adult muscle stem cells. Cell Stem Cell 13:590-601.

37. von Maltzahn J, AE Jones, RJ Parks and MA Rudnicki. (2013). Pax7 is critical for the normal function of satellite cells in adult skeletal muscle. Proc Natl Acad Sci U S A 110:16474-16479.

38. Wang J and I Conboy. (2009). Embryonic vs. adult myogenesis: challenging the 'regeneration recapitulates development' paradigm. J Mol Cell Biol 2:1-4.

39. Relaix F and PS Zammit. (2012). Satellite cells are essential for skeletal muscle regeneration: the cell on the edge returns centre stage. Development 139:2845-2856.

40. Sambasivan R, R Yao, A Kissenpfennig, L Van Wittenberghe, A Paldi, B Gayraud-Morel, H Guenou, B Malissen, S Tajbakhsh and A Galy. (2011). Pax7-expressing satellite cells are indispensable for adult skeletal muscle regeneration. Development 138:3647-3656.

41. McCarthy JJ, J Mula, M Miyazaki, R Erfani, K Garrison, AB Farooqui, R Srikuea, BA Lawson, B Grimes, et al. (2011). Effective fiber hypertrophy in satellite celldepleted skeletal muscle. Development 138:3657-3666.

42. Murphy MM, JA Lawson, SJ Mathew, DA Hutcheson and G Kardon. (2011). Satellite cells, connective tissue fibroblasts and their interactions are crucial for muscle regeneration. Development 138:3625-3637.

43. Lepper C, TA Partridge and CM Fan. (2011). An absolute requirement for Pax7-positive satellite cells in acute injury-induced skeletal muscle regeneration. Development 138:3639-3646.

44. Eckardt S, KJ McLaughlin and H Willenbring. (2011). Mouse chimeras as a system to investigate development, cell and tissue function, disease mechanisms and organ regeneration. Cell Cycle 10:2091-2099.

45. Eggan K, A Rode, I Jentsch, C Samuel, T Hennek, H Tintrup, B Zevnik, J Erwin, J Loring, et al. (2002). Male and female mice derived from the same embryonic stem cell clone by tetraploid embryo complementation. Nat Biotechnol 20:455-459.

46. Wang Z and R Jaenisch. (2004). At most three ES cells contribute to the somatic lineages of chimeric mice and of mice produced by ES-tetraploid complementation. Dev Biol 275:192-201.

47. Zhou D, JX Ren, TM Ryan, NP Higgins and TM Townes. (2004). Rapid tagging of endogenous mouse genes by recombineering and ES cell complementation of tetraploid blastocysts. Nucleic Acids Res 32:e128.

48. Gropp M, V Shilo, G Vainer, M Gov, Y Gil, H Khaner, L Matzrafi, M Idelson, J Kopolovic, NB Zak and BE Reubinoff. (2012). Standardization of the teratoma assay for analysis of pluripotency of human ES cells and biosafety of their differentiated progeny. PLoS One 7:e45532.

49. Borchin B, J Chen and T Barberi. (2013). Derivation and FACS-Mediated Purification of PAX3+/PAX7+ Skeletal muscle precursors from human pluripotent stem cells. Stem Cell Rep 1:620-631.

50. Shelton M, J Metz, J Liu, RL Carpenedo, S-P Demers, WL Stanford and IS Skerjanc. (2014). Derivation and expansion of PAX7-positive muscle progenitors from human and mouse embryonic stem cells. Stem Cell Rep 3:516-529.

51. Chal J, M Oginuma, Z Al Tanoury, B Gobert, O Sumara, A Hick, F Bousson, Y Zidouni, C Mursch, et al. (2015). Differentiation of pluripotent stem cells to muscle fiber to model Duchenne muscular dystrophy. Nat Biotechnol 33: 962-969.
52. Close B, K Banister, V Baumans, EM Bernoth, N Bromage, J Bunyan, W Erhardt, P Flecknell, N Gregory, et al. (1996). Recommendations for euthanasia of experimental animals: Part 1. DGXI of the European Commission. Lab Anim 30:293-316.

53. Close B, K Banister, V Baumans, EM Bernoth, N Bromage, J Bunyan, W Erhardt, P Flecknell, N Gregory, et al. (1997). Recommendations for euthanasia of experimental animals: Part 2. DGXT of the European Commission. Lab Anim 31:1-32.

54. Robertson E. (1987). Embryo-derived stem cell lines. In: Teratocarcinomas and Embryonic Stem Cells: A Practical Approach. Robertson, E ed. Oxford University Press, Oxford, England, pp 71-112.

55. Fulton BP and DG Whittingham. (1978). Activation of mammalian oocytes by intracellular injection of calcium. Nature 273:149-151.

56. Barberi T, M Bradbury, Z Dincer, G Panagiotakos, ND Socci and L Studer. (2007). Derivation of engraftable skeletal myoblasts from human embryonic stem cells. Nat Med 13:642-648.

57. Stavropoulos ME, I Mengarelli and T Barberi. (2009). Differentiation of multipotent mesenchymal precursors and skeletal myoblasts from human embryonic stem cells. Curr Protoc Stem Cell Biol Chapter 1:Unit 1F 8.

58. Kennedy KA, T Porter, V Mehta, SD Ryan, F Price, V Peshdary, C Karamboulas, J Savage, TA Drysdale, et al. (2009). Retinoic acid enhances skeletal muscle progenitor formation and bypasses inhibition by bone morphogenetic protein 4 but not dominant negative beta-catenin. BMC Biol 7:67.

59. Wobus AM, K Guan, HT Yang and KR Boheler. (2002). Embryonic stem cells as a model to study cardiac, skeletal muscle, and vascular smooth muscle cell differentiation. Methods Mol Biol 185:127-156.

60. Ciemerych MA, Q Yu, K Szczepanska and P Sicinski. (2008). CDK4 activity in mouse embryos expressing a single D-type cyclin. Int J Dev Biol 52:299-305.

61. Tamaki T, A Akatsuka, K Ando, Y Nakamura, H Matsuzawa, T Hotta, RR Roy and VR Edgerton. (2002). Identification of myogenic-endothelial progenitor cells in the interstitial spaces of skeletal muscle. J Cell Biol 157: 571-577.

62. Hogan BF, F Constantini and E Lacy. (1986). Manipulating the Mouse Embryo: A Laboratory Manual. Cold Spring Harbor Laboratory, Cold Spring Harbor, NY.

63. Livak KJ and TD Schmittgen. (2001). Analysis of relative gene expression data using real-time quantitative PCR and the 2(T)(-Delta Delta C) method. Methods 25:402-408.

64. Bolstad BM, RA Irizarry, M Astrand and TP Speed. (2003). A comparison of normalization methods for high density oligonucleotide array data based on variance and bias. Bioinformatics 19:185-193.

65. Kawase E, H Suemori, N Takahashi, K Okazaki, K Hashimoto and N Nakatsuji. (1994). Strain Difference in Establishment of Mouse Embryonic Stem (Es) Cell-Lines. Int J Dev Biol 38:385-390.

66. Doetschman TC, H Eistetter, M Katz, W Schmidt and R Kemler. (1985). The in vitro development of blastocystderived embryonic stem cell lines: formation of visceral yolk sac, blood islands and myocardium. J Embryol Exp Morphol 87:27-45.

67. Pease S and RL Williams. (1990). Formation of germ-line chimeras from embryonic stem cells maintained with re- 
combinant leukemia inhibitory factor. Exp Cell Res 190:209-211.

68. Salani S, C Donadoni, F Rizzo, N Bresolin, GP Comi and S Corti. (2012). Generation of skeletal muscle cells from embryonic and induced pluripotent stem cells as an in vitro model and for therapy of muscular dystrophies. J Cell Mol Med 16:1353-1364.

69. Rohwedel J, K Guan and AM Wobus. (1999). Induction of cellular differentiation by retinoic acid in vitro. Cells Tissues Organs 165:190-202.

70. Kataoka H, N Takakura, S Nishikawa, K Tsuchida, H Kodama, T Kunisada, W Risau, T Kita and SI Nishikawa. (1997). Expressions of PDGF receptor alpha, c-Kit and Flk1 genes clustering in mouse chromosome 5 define distinct subsets of nascent mesodermal cells. Dev Growth Differ 39:729-740.

71. Moore JW, C Dionne, M Jaye and JL Swain. (1991). The Messenger-Rnas Encoding Acidic Fgf, Basic Fgf and Fgf receptor are coordinately down-regulated during myogenic differentiation. Development 111:741-748.

72. Pevny LH, S Sockanathan, M Placzek and R LovellBadge. (1998). A role for SOX1 in neural determination. Development 125:1967-1978.

73. Morrisey EE, Z Tang, K Sigrist, MM Lu, F Jiang, HS Ip and MS Parmacek. (1998). GATA6 regulates HNF4 and is required for differentiation of visceral endoderm in the mouse embryo. Genes Dev 12:3579-3590.

74. Cohenhaguenauer O, PJR Barton, VC Nguyen, A Cohen, M Masset, M Buckingham and J Frezal. (1989). Chromosomal assignment of 2 myosin alkali light-chain genes encoding the ventricular slow skeletal-muscle isoform and the atrial fetal muscle isoform (Myl3, Myl4). Hum Genet 81:278-282.

75. Biressi S, E Tagliafico, G Lamorte, S Monteverde, E Tenedini, E Roncaglia, S Ferrari, S Ferrari, MGCD Angelis, S Tajbakhsh and G Cossu. (2007). Intrinsic phenotypic diversity of embryonic and fetal myoblasts is revealed by genome-wide gene expression analysis on purified cells. Dev Biol 304:633-651.

76. Messina G, S Biressi, S Monteverde, A Magli, M Cassano, L Perani, E Roncaglia, E Tagliafico, L Starnes, et al. (2010). Nfix regulates fetal-specific transcription in developing skeletal muscle. Cell 140:554-566.

77. Colas AR, WL McKeithan, TJ Cunningham, PJ Bushway, LX Garmire, G Duester, S Subramaniam and M Mercola. (2012). Whole-genome microRNA screening identifies let-7 and mir-18 as regulators of germ layer formation during early embryogenesis. Genes Dev 26:2567-2579.

78. Wang Y, S Baskerville, A Shenoy, JE Babiarz, L Baehner and R Blelloch. (2008). Embryonic stem cell-specific microRNAs regulate the G1-S transition and promote rapid proliferation. Nat Genet 40:1478-1483.

79. Melton C, RL Judson and R Blelloch. (2010). Opposing microRNA families regulate self-renewal in mouse embryonic stem cells. Nature 463:621-626.

80. Xu N, T Papagiannakopoulos, G Pan, JA Thomson and KS Kosik. (2009). MicroRNA-145 regulates OCT4, SOX2, and KLF4 and represses pluripotency in human embryonic stem cells. Cell 137:647-658.

81. Naguibneva I, M Ameyar-Zazoua, A Polesskaya, S Ait-SiAli, R Groisman, M Souidi, S Cuvellier and A HarelBellan. (2006). The microRNA miR-181 targets the homeobox protein Hox-A11 during mammalian myoblast differentiation. Nat Cell Biol 8:278-284.
82. Chen JF, EM Mandel, JM Thomson, Q Wu, TE Callis, SM Hammond, FL Conlon and DZ Wang. (2006). The role of microRNA-1 and microRNA-133 in skeletal muscle proliferation and differentiation. Nat Genet 38:228-233.

83. Zhang D, X Li, C Chen, Y Li, L Zhao, Y Jing, W Liu, X Wang, Y Zhang, et al. (2012). Attenuation of p38-mediated miR-1/133 expression facilitates myoblast proliferation during the early stage of muscle regeneration. PloS One 7: e41478.

84. Kano M, N Seki, N Kikkawa, L Fujimura, I Hoshino, Y Akutsu, T Chiyomaru, H Enokida, M Nakagawa and $\mathrm{H}$ Matsubara. (2010). miR-145, miR-133a and miR-133b: tumor-suppressive miRNAs target FSCN1 in esophageal squamous cell carcinoma. Int J Cancer 127:2804-2814.

85. Kassar-Duchossoy L, E Giacone, B Gayraud-Morel, A Jory, D Gomes and S Tajbakhsh. (2005). Pax3/Pax7 mark a novel population of primitive myogenic cells during development. Genes Dev 19:1426-1431.

86. Montarras D, J Morgan, C Collins, F Relaix, S Zaffran, A Cumano, T Partridge and M Buckingham. (2005). Direct isolation of satellite cells for skeletal muscle regeneration. Science 309:2064-2067.

87. Boutet SC, TH Cheung, NL Quach, L Liu, SL Prescott, A Edalati, K Iori and TA Rando. (2012). Alternative polyadenylation mediates microRNA regulation of muscle stem cell function. Cell Stem Cell 10:327-336.

88. Horst D, S Ustanina, C Sergi, G Mikuz, H Juergens, T Braun and E Vorobyov. (2006). Comparative expression analysis of Pax 3 and Pax 7 during mouse myogenesis. Int $\mathrm{J}$ Dev Biol 50:47-54.

89. Dekel I, Y Magal, S Pearson-White, CP Emerson and M Shani. (1992). Conditional conversion of ES cells to skeletal muscle by an exogenous MyoD1 gene. New Biol 4: 217-224.

90. Shani M, A Faerman, CP Emerson, S Pearson-White, I Dekel and Y Magal. (1992). The consequences of a constitutive expression of MyoD1 in ES cells and mouse embryos. Symp Soc Exp Biol 46:19-36.

91. Armour C, K Garson and MW McBurney. (1999). Cell-cell interaction modulates myoD-induced skeletal myogenesis of pluripotent P19 cells in vitro. Exp Cell Res 251:79-91.

92. Gianakopoulos PJ, V Mehta, A Voronova, Y Cao, Z Yao, J Coutu, X Wang, MS Waddington, SJ Tapscott and IS Skerjanc. (2011). MyoD directly up-regulates premyogenic mesoderm factors during induction of skeletal myogenesis in stem cells. J Biol Chem 286:2517-2525.

93. Craft AM, DM Krisky, JB Wechuck, EK Lobenhofer, Y Jiang, DP Wolfe and JC Glorioso. (2008). Herpes simplex virus-mediated expression of Pax3 and MyoD in embryoid bodies results in lineage-Related alterations in gene expression profiles. Stem Cells 26:3119-3129.

94. Darabi R, FN Santos, A Filareto, W Pan, R Koene, MA Rudnicki, M Kyba and RC Perlingeiro. (2011). Assessment of the myogenic stem cell compartment following transplantation of pax3/pax7-induced embryonic stem cell-derived progenitors. Stem Cells 29:777-790.

95. Darabi R, W Pan, D Bosnakovski, J Baik, M Kyba and RC Perlingeiro. (2011). Functional myogenic engraftment from mouse iPS cells. Stem Cell Rev 7:948-957.

96. Darabi R, FN Santos and RC Perlingeiro. (2008). The therapeutic potential of embryonic and adult stem cells for skeletal muscle regeneration. Stem Cell Rev 4:217-225.

97. Darabi R, K Gehlbach, RM Bachoo, S Kamath, M Osawa, KE Kamm, M Kyba and RC Perlingeiro. (2008). Func- 
tional skeletal muscle regeneration from differentiating embryonic stem cells. Nat Med 14:134-143.

98. Darabi R, RW Arpke, S Irion, JT Dimos, M Grskovic, M Kyba and RCR Perlingeiro. (2012). Human ES- and iPS-Derived Myogenic Progenitors Restore DYSTROPHIN and Improve Contractility upon Transplantation in Dystrophic Mice. Cell Stem Cell 10:610-619.

99. Boheler KR, J Czyz, D Tweedie, HT Yang, SV Anisimov and AM Wobus. (2002). Differentiation of pluripotent embryonic stem cells into cardiomyocytes. Circ Res 91: 189-201.

100. Buckingham M and SD Vincent. (2009). Distinct and dynamic myogenic populations in the vertebrate embryo. Curr Opin Genet Dev 19:444-453.

101. Li X, J Zhang, L Gao, S McClellan, MA Finan, TW Butler, LB Owen, GA Piazza and Y Xi. (2011). MiR181 mediates cell differentiation by interrupting the Lin28 and let-7 feedback circuit. Cell Death Differ 19: 378-386.

102. Hirai H, M Verma, S Watanabe, C Tastad, Y Asakura and A Asakura. (2010). MyoD regulates apoptosis of myoblasts through microRNA-mediated down-regulation of Pax3. J Cell Biol 191:347-365.

103. Kim HK, YS Lee, U Sivaprasad, A Malhotra and A Dutta. (2006). Muscle-specific microRNA miR-206 promotes muscle differentiation. J Cell Biol 174:677-687.

104. Rohwedel J, V Maltsev, E Bober, HH Arnold, J Hescheler and AM Wobus. (1994). Muscle cell differentiation of embryonic stem cells reflects myogenesis in vivo: developmentally regulated expression of myogenic determina- tion genes and functional expression of ionic currents. Dev Biol 164:87-101.

105. Newman AM and JB Cooper. (2010). Lab-specific gene expression signatures in pluripotent stem cells. Cell Stem Cell 7:258-262.

106. Bock C, E Kiskinis, G Verstappen, H Gu, G Boulting, ZD Smith, M Ziller, GF Croft, MW Amoroso, et al. (2011). Reference Maps of human ES and iPS cell variation enable high-throughput characterization of pluripotent cell lines. Cell 144:439-452.

107. Humpherys D, K Eggan, H Akutsu, K Hochedlinger, WM Rideout, 3rd, D Biniszkiewicz, R Yanagimachi and R Jaenisch. (2001). Epigenetic instability in ES cells and cloned mice. Science 293:95-97.

Address correspondence to:

Maria A. Ciemerych

Department of Cytology

Institute of Zoology

Faculty of Biology

University of Warsaw

Miecznikowa 1

Warsaw 02-096

Poland

E-mail: ciemerych@biol.uw.edu.pl

Received for publication May 3, 2015

Accepted after revision December 7, 2015

Prepublished on Liebert Instant Online December 9, 2015 